Research Article

\title{
Shear Mechanical Behaviours and Multistrength Parameter Characteristics of Fault Gouge
}

\author{
Han Bao $\mathbb{D}^{1},{ }^{1}$ Qun Qi $\left(\mathbb{D},{ }^{1}\right.$ Hengxing Lan, ${ }^{2,3}$ Changgen Yan $\mathbb{D}^{1},{ }^{1}$ Wei Xu $\mathbb{D}^{1},{ }^{1}$ Xin Liu, ${ }^{3}$ \\ and Langping $\mathbf{L i}^{2}$ \\ ${ }^{1}$ School of Highway, Chang'an University, Xi'an, Shaanxi 710064, China \\ ${ }^{2}$ State Key Laboratory of Resources and Environmental Information System, \\ Institute of Geographic Sciences and Natural Resources Research, Chinese Academy of Sciences, Beijing 100101, China \\ ${ }^{3}$ School of Geological Engineering and Geomatics, Chang'an University, Xi'an, Shaanxi 710064, China
}

Correspondence should be addressed to Han Bao; baohangeo@163.com and Qun Qi; 2017221102@chd.edu.cn

Received 11 April 2019; Revised 19 September 2019; Accepted 19 October 2019; Published 18 November 2019

Academic Editor: Emilio García-Taengua

Copyright $\odot 2019$ Han Bao et al. This is an open access article distributed under the Creative Commons Attribution License, which permits unrestricted use, distribution, and reproduction in any medium, provided the original work is properly cited.

Fault gouge has special mechanical properties and remarkable engineering effects. Using a ring shear test, the strength properties of the differently colored remolded fault gouges of the Shendaogou Fault in Yan'an were studied by changing moisture contents and normal stresses. Chlorite and illite are the main clay minerals in fault gouges; differences in mineral composition make fault gouges appear in different colors. Besides clay minerals, the dried fault gouges disintegration in water is also due to the transformation of gypsum. The gradation of green fault gouge and multicolor fault gouge is better than that of the red fault gouge, while the fault gouges' strain softening properties become weaker as the coarse grain content increases. Affected by water content and normal stress, the shear planes can be divided into three failure modes: peeling failure, grooved failure, and sliding failure. With the increase of water content, there will be a significant weakening on cohesion and friction angle. A new parameter, the "Normal Stress Threshold (NST)," is introduced as a critical value for the emergence of the strain hardening phenomenon, and the NSTs of different fault gouges are significantly different. The functions obtained from the relation of residual strength, peak strength, and normal stress can be used to calculate shear strength parameters under any normal stresses. In addition, the residual strength of fault gouge is obviously different from clay and loess, which can be qualitatively explained by clay particle contents.

\section{Introduction}

As one of the most important weak zones in rock mass, fault zone is a basic condition that controls engineering safety in mountain areas [1-3]. Studies on fault gouges' shear properties are helpful in explaining and predicting disaster risk in fault crossing areas [4].

In the 1980s, Geng et al. [5] explored the physical and mechanical properties of 75 kinds of fault gouges in five fault zones and analyzed their mechanical parameters, such as volume modulus, elastic modulus, elastic wave velocity, compressive strength, shear strength, and residual volumetric strain. The strength of the San Andreas Fault gouge was measured within $200 \mathrm{MPa}$ confining pressure, and the results showed that the fault gouge strength was reduced by the pseudopore pressure generated by loosely bound water in clays [6]. In recent years, some scholars used doubledirect shear tests to investigate the relationship between frictional strength and fabric characteristics of fault gouge, which indicated that the frictional strength showed a negative correlation with clay content and particle size [7, 8]. Liu et al. [9] divided the shear strength properties into four types according to their geotechnical parameters and established a probabilistic prediction method for shear strength. Li and Deng [10] studied the mechanical properties of an undisturbed fault gouge in the Longmenshan Fault zone. The interface of the different color fault gouge was found to be the weak point of shear strength. Zhang and $\mathrm{He}$ [11] researched the frictional sliding behavior of clay minerals and their influences on fault mechanical properties and found that the fault strength showed a negative correlation with clay content, and the difference in clay mineral 
distribution would result in different weak degrees of fault strength.

A fault zone can be a channel for groundwater migration $[12,13]$, and groundwater thus plays an important role in a fault gouge's physical and mechanical properties. The change of water content leads to prominent changes in mechanical behaviors of soil [14-16]. Morrow et al. [17] conducted triaxial sliding tests on 15 different single-mineral fault gouges with different water-adsorbing affinities, and their results confirmed that the fault gouge friction strength is related to the water absorption capacity of minerals. Under high-velocity rotary shear tests at $1 \mathrm{~m} / \mathrm{s}$, the dry fault gouge showed a prolonged strengthening stage prior to dynamic weakening, whereas the wet fault gouge weakened instantaneously [18]. By studying the relationship between the strength parameters and water content, Liu and Nie [19] revealed the existence of an inflection point when the fault gouge strength index changed with water content and established the relationship between water content of the inflection point and Atterberg limits. Wang et al. [20] conducted direct shear tests to analyze the influence of water content and cementation on fault gouge strength. Their study found that the cohesion under different cementation values can be divided into three stages based on change in water content.

The sliding property is one of the main aspects of fault gouge research. Studies on the mechanical properties of fault gouges are mostly dependent on a direct shear test or triaxial test $[7-10,17,20-26]$, while fewer studies on shear slip behaviors. As a test equipment for studying soil mechanical properties under a large displacement, the ring shear apparatus can dynamically control the normal stress and shear rate during the test and can keep stress uniformity on the shear plane [27]. In this paper, the slipping properties of fault gouges are analyzed during the ring shear test, and the strength parameters under different water contents are obtained, which can be helpful in judging the mechanical behavior of fault gouges and studying the engineering geological mechanical effects of fault zones.

\section{Geological Background and Occurrence State of Fault Gouge}

2.1. Geological Background. The Shendaogou Fault is located in Yan'an, Shaanxi Province, China. It is part of the hilly and gully region of the Loess Plateau, where the residual loess tablelands and gullies are developed [28]. In the study area, the basement fluctuation is complex, and the strata are mainly mesozoic sedimentary rocks. The outcropped bedrock strata include Jurassic livid sandstone, upper cretaceous thick coarse sandstone, and lower cretaceous thin fine sandstone. The sandstone is interbedded with thin mudstone and shale [29]. The strata are distributed nearly horizontally and are often outcropped in gullies. The distribution of faults in Yan'an has characteristics of east-west zoning and northsouth clustering; in addition, the fault zones mainly develop in NE and NW-NWW directions.

The Shendaogou Fault is a normal fault that strikes NE. It outcrops along the gullies in the sand-mudstone interbeds with an average elevation of $1213 \mathrm{~m}$. The study area and fault distribution are shown in Figure 1.

The fault fracture at the edge of the slope reduces the slope stability, which is one of the leading factors causing landslides. There are three landslides with high slip cliffs and wide landslide platforms along the Shendaogou Fault (Figure 2). The largest is landslide I, which is $320 \mathrm{~m}$ in length and $300 \mathrm{~m}$ in width. The length of landslide II is $160 \mathrm{~m}$, and the width is approximately $210 \mathrm{~m}$. Landslide III is $110 \mathrm{~m}$ long and approximately $270 \mathrm{~m}$ wide at the foot.

The fault tectonic movement on both sides of the gully is marked. The bedrock elevation along the east side is approximately $1122 \mathrm{~m}$, while on the west side it is $1104 \mathrm{~m}$. In the fault zone, the red fault gouge and green fault gouge are distributed without an obvious boundary (Figure 3(a)), while the red mudstone and yellow-green mudstone are clearly separated in the nonfault zone (Figure 3(b)).

2.2. Occurrence State of Fault Gouge. The sampling point of the fault gouge is located in Ansai District, Yan'an (N36.578, $\mathrm{E} 109.307^{\circ}$, elevation $\left.1121 \mathrm{~m}\right)$. The samples are fresh, unweathered fault gouges with a natural water content of $13 \%$ to $17 \%$. Fault gouges have significant differences in color, which can be divided into three types: (1) red fault gouge; (2) green fault gouge; (3) complex cemented fault gouge with various colors (referred to as multicolor fault gouge) (Figure 4). Influenced by the original interbedded strata, fault gouges with different colors alternately appear and distribute in blocks. There is no obvious boundary among different colors of fault gouges. The uneven color distribution indicates the complexity of the fault gouge formation process and its physical-mechanical properties.

A fault gouge is the direct product of fault activity, which leaves a special structural trace. The main slip surface of Shendaogou Fault has not been found in situ because of the large width of fault zone. However, small slip fractures with smooth slip surfaces are widely developed in fault gouges (Figures 4 and 5). In fault gouges, the widely distributed smooth sliding surfaces indicate a remarkable sliding structure. The sliding surfaces of dip-slip fault (normal fault or reverse fault) usually display a shape of arc-shaped waviness, while strike-slip fault usually has planar sliding surfaces [30]. The sliding scratches developed in the samples present an obvious arc-shaped waviness (Figure 5), which indicates that the Shendaogou Fault is a dip-slip fault.

\section{Physical Characteristics and Mineral Analysis}

3.1. Basic Physical Parameters. The fault gouge's disintegration is significantly improved after drying. The dried fault gouges of different colors disintegrate completely and release bubbles immediately after being soaked in water. The fault gouge particles with different colors can be obtained after drying again, and the process is shown in Figure 6.

The dry density $\left(\rho_{\mathrm{d}}\right)$ and particle specific gravity $\left(G_{\mathrm{s}}\right)$ of different color fault gouge were measured, which are shown in Table 1. $\rho_{\mathrm{d}}$ was measured by oven drying method with cutting ring, which can be expressed as 


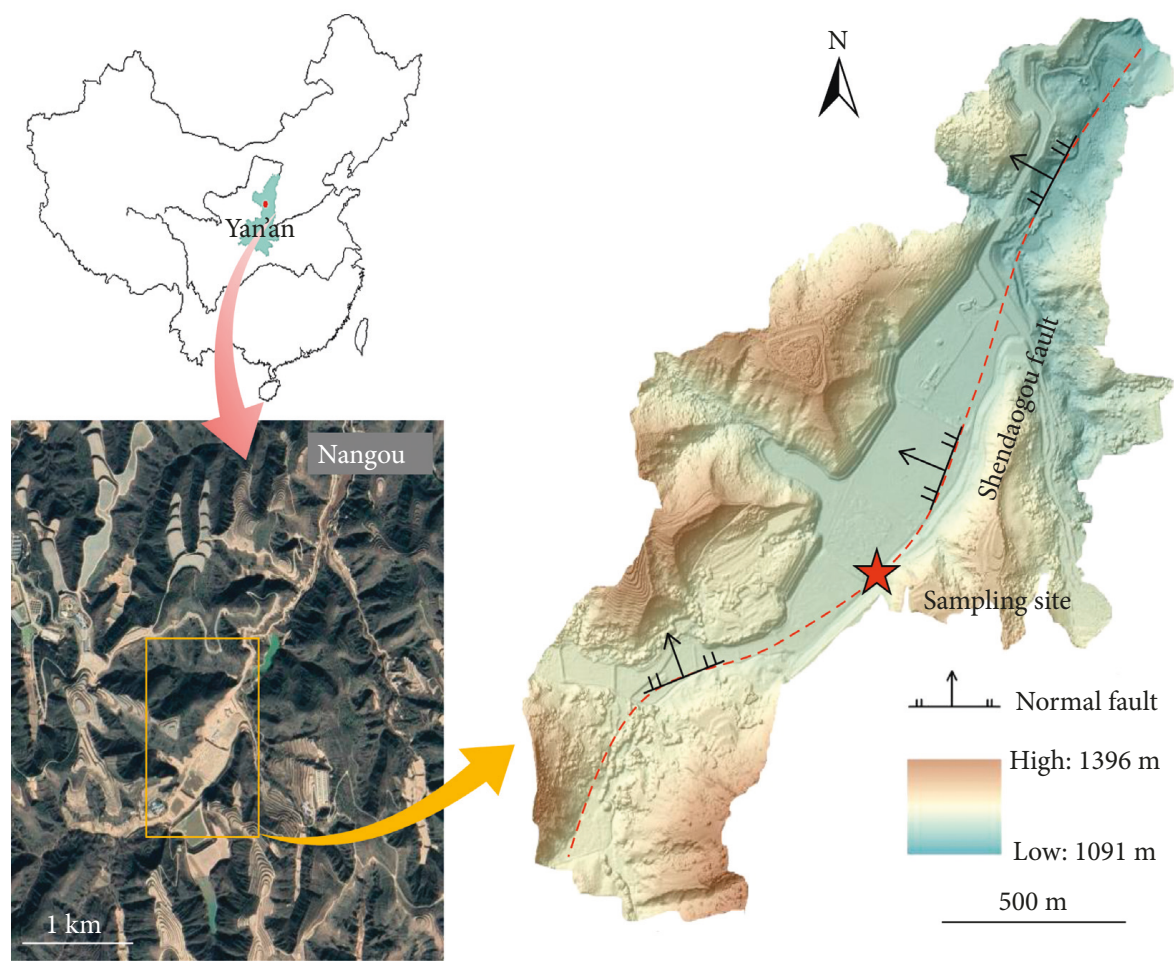

FIgURe 1: Study area and fault distribution.
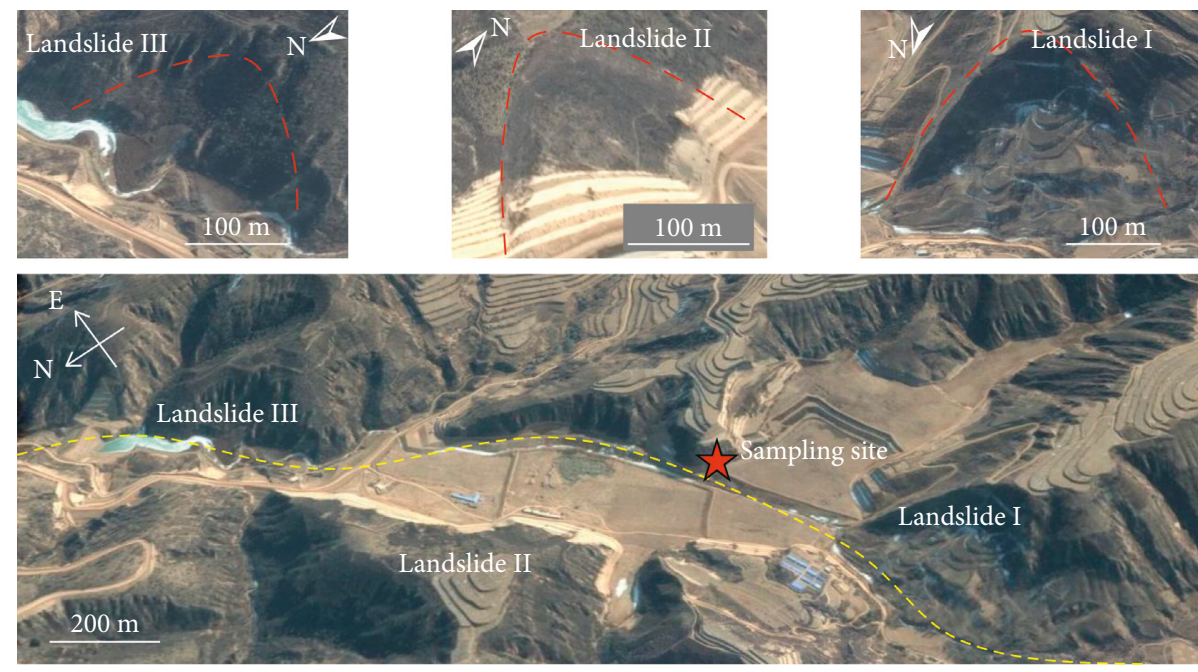

Figure 2: Distribution of landslides along fault zones.

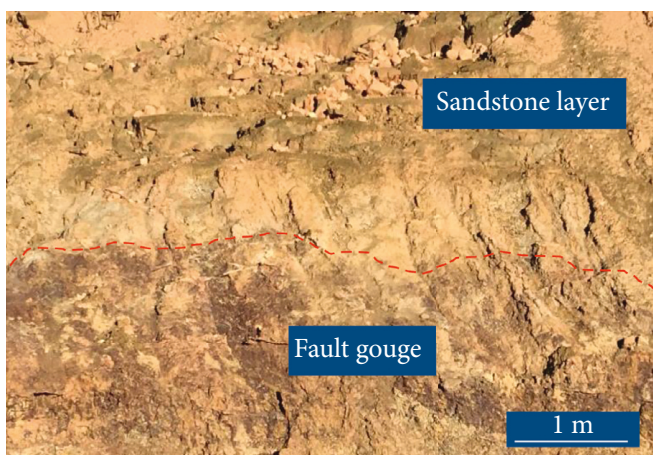

(a)

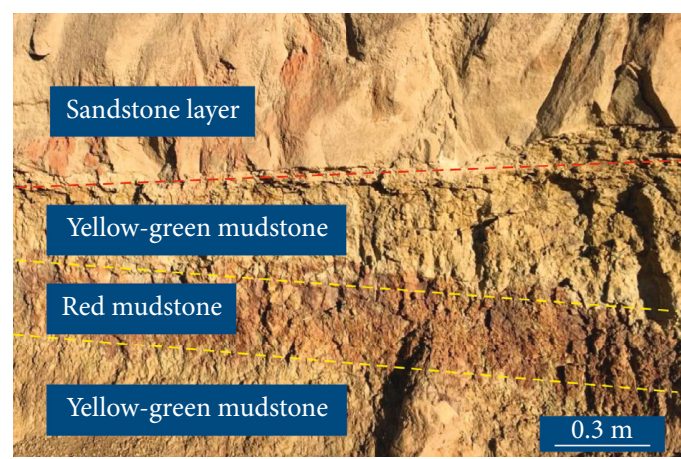

(b)

FIgURE 3: Strata characteristics of the fault zone and nonfault zone. 


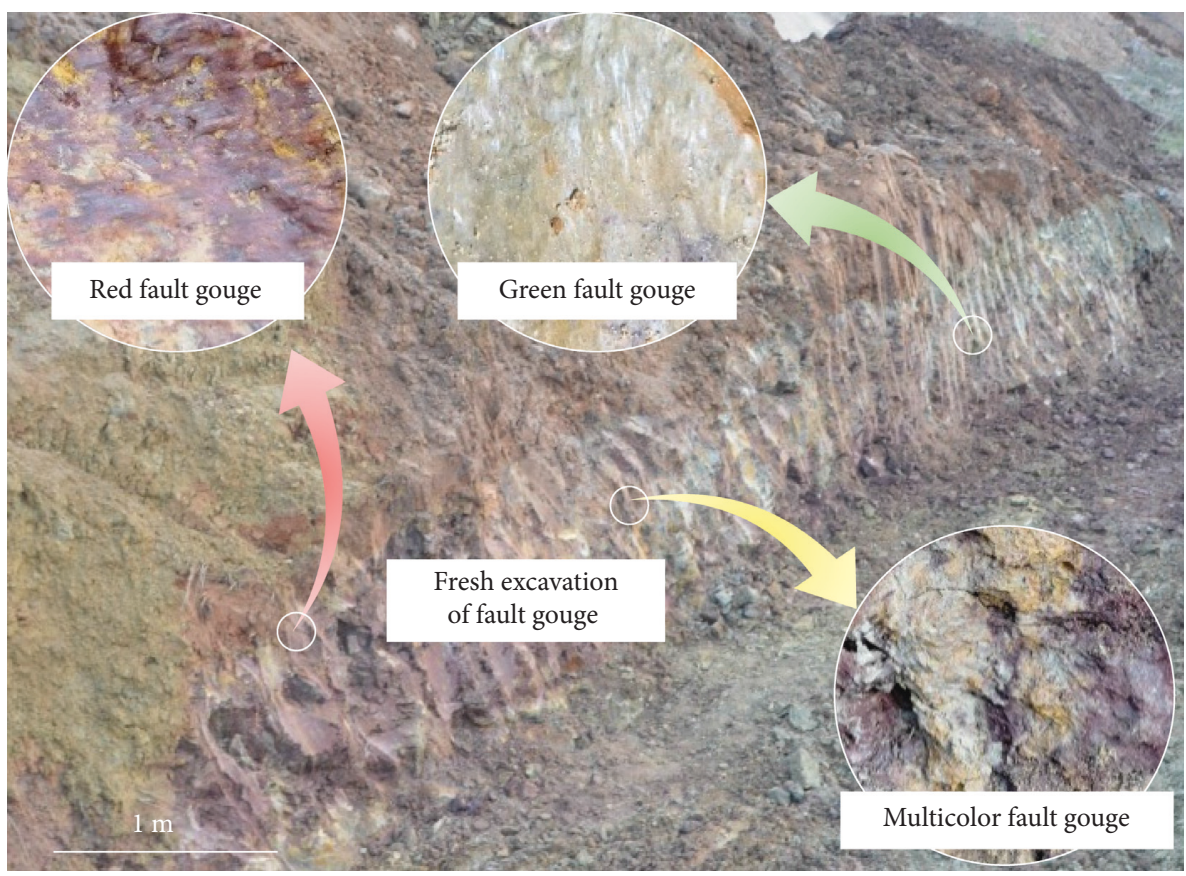

FIGURE 4: Fault gouges of different colors on site.

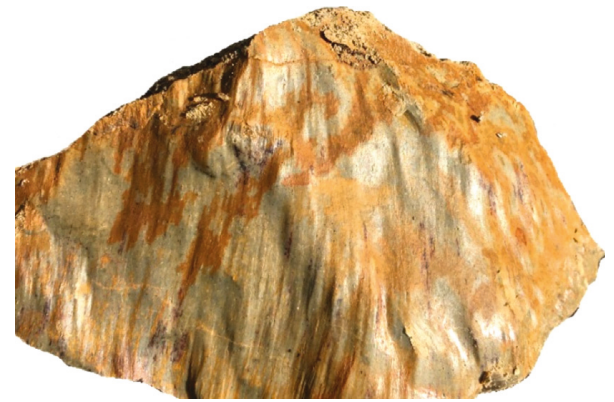

FigURE 5: Friction mirror surface of fault gouge.
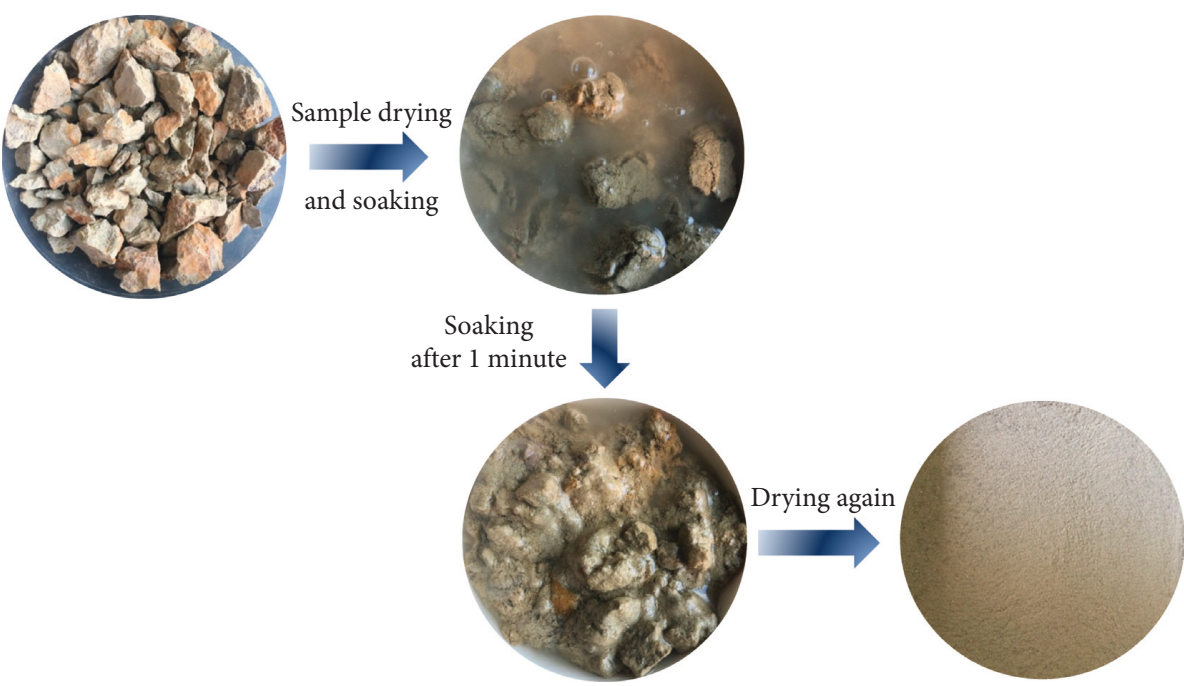

Figure 6: Disintegration and drying of the fault gouge. 
TABLE 1: Fault gouge physical parameters and parameters.

\begin{tabular}{|c|c|c|c|c|c|}
\hline Fault gouge types & $\rho_{\mathrm{d}}\left(\mathrm{g} \cdot \mathrm{cm}^{3}\right)$ & $G_{\mathrm{s}}\left(\mathrm{g} \cdot \mathrm{cm}^{3}\right)$ & $\operatorname{SSA}\left(\mathrm{m}^{2} \cdot \mathrm{g}^{-1}\right)$ & $C_{\mathrm{u}}$ & $C_{\mathrm{s}}$ \\
\hline Red fault gouge & 1.97 & 2.69 & 0.488 & 8.36 & 0.678 \\
\hline Multicolor fault gouge & 2.06 & 2.68 & 0.286 & 10.160 & 1.219 \\
\hline Green fault gouge & 2.11 & 2.66 & 0.342 & 10.980 & 1.033 \\
\hline
\end{tabular}

$$
\rho_{\mathrm{d}}=\frac{m_{\mathrm{s}}}{V}
$$

where $V$ is the volume measured by cutting ring and $m_{\mathrm{s}}$ is the mass of fault gouge sample after dried for 12 hours at $105^{\circ} \mathrm{C}$. The fault gouge's dry density is 1.97 to $2.11 \mathrm{~g} / \mathrm{cm}^{3}$, which is obviously different for the different colored gouges and is much higher than that of common soils. However, the particle specific gravity is very close, which is 2.66 to $2.69 \mathrm{~g} / \mathrm{cm}^{3}$.

The particle size distribution curves and cumulative grading curves of the different fault gouges (Figure 7) were obtained by using a Bettersize-2000 laser particle size analyzer. The particle size distribution curves of the multicolor fault gouge and green fault gouge are similar, as they both have a single peak, while the curve of the red fault gouge has double peaks. The order of coarse particle content is multicolor fault gouge $>$ green fault gouge $>$ red fault gouge.

In addition, the specific surface area (SSA), nonuniformity coefficient $\left(C_{\mathrm{u}}\right)$, and curvature coefficient $\left(C_{\mathrm{s}}\right)$ of different fault gouges also present differences, and the results are shown in Table 1.

$C_{\mathrm{u}}$ and $C_{\mathrm{s}}$ are important indexes to describe gradation curve. $C_{\mathrm{u}}$ reflects the distribution of different particle sizes, $C_{s}$ is an index to describe the overall shape of a cumulative curve, which can be expressed as

$$
\begin{aligned}
& C_{\mathrm{u}}=\frac{d_{60}}{d_{10}}, \\
& C_{\mathrm{s}}=\frac{d_{30}^{2}}{d_{60} d_{10}},
\end{aligned}
$$

where $d_{10}, d_{30}$, and $d_{60}$ are the particle sizes at cumulative percentage of $10 \%, 30 \%$, and $60 \%$, respectively. In engineering, soil gradation is good when $C_{\mathrm{u}} \geq 5$ and $1 \leq C_{\mathrm{s}} \leq 3$ are satisfied simultaneously. Based on the analysis on gradation parameters, the multicolor fault gouge and green fault gouge have a strong gradation with $C_{\mathrm{u}}>5$ and $C_{\mathrm{s}}=1$ to 3 . Although the $C_{\mathrm{u}}$ of the red fault gouge is large than 5 , due to the abrupt change of median particle size content, the $C_{\mathrm{s}}$ of the red fault gouge is less than 1 . Therefore, the gradation of the red fault gouge is worse than other two types.

3.2. Analysis of Mineral Components. Exploring the mineral components can not only explain the differences in color of fault gouges but also help to analyze their mechanical behaviors. In this study, the fault gouges were detected by $\mathrm{X}$-ray diffraction (XRD), and the diffraction patterns and mineral components of three different color fault gouges are shown in Figure 8.

In Figure 8 , it can be seen that the diffraction peak of quartz is the highest in nonclay minerals, while the

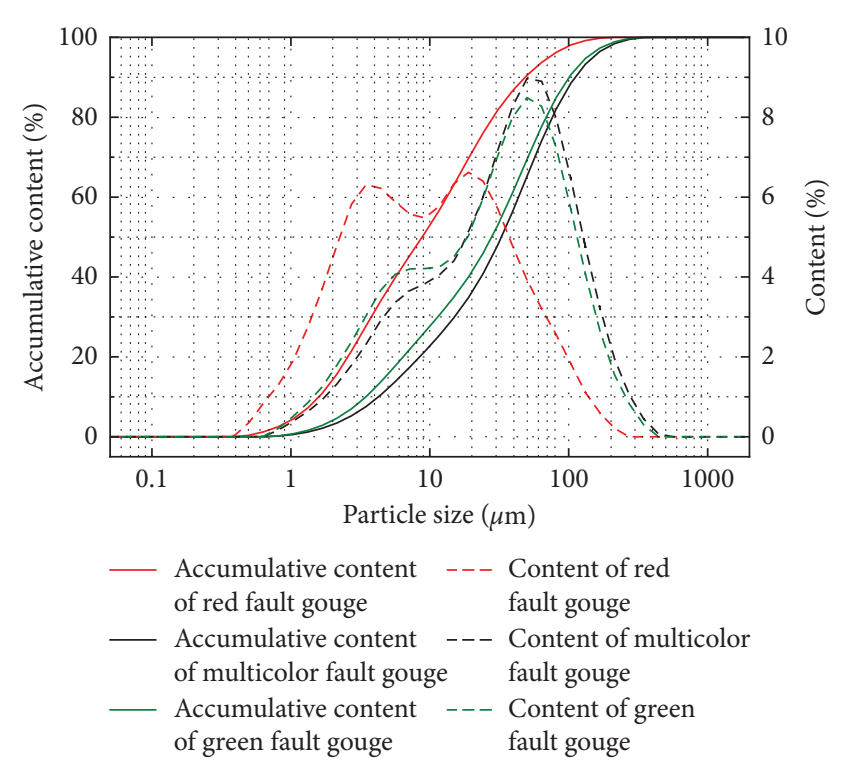

Figure 7: Gradation curves of different fault gouges.

diffraction peak of illite is the most significant in clay minerals. The existence of quartz greatly reduces the diffraction peak strength of clay minerals, which has influence on the semiquantitative analysis of mineral component. In this paper, all minerals in Figure 8 were analyzed semiquantitatively, and the results are shown in Table 2.

Quartz, muscovite, and albite are the main nonclay minerals in fault gouges, among which quartz is the most abundant. The clay minerals are mainly illite, kaolinite, and chlorite, while the content of montmorillonite is less (not shown in Table 2). The high content of illite and kaolinite may be transformed from muscovite and quartz [31]. The deep-red color presented by red fault gouge is due to the existence of hematite containing much $\mathrm{Fe}^{3+}$, while the greygreen color presented by green fault gouge is due to high content of chlorite and without hematite.

Clay mineral expansion and carbonate ion dissolution have long been considered as the main driving force for rock disintegration. This is because rocks with higher clay mineral content tend to absorb more water which weakens the intergranular bonds and promotes disintegration [32]. In addition, gypsum $\left(\mathrm{CaSO}_{4} \cdot 2 \mathrm{H}_{2} \mathrm{O}\right)$ can also explain why dried fault gouge is easy to disintegrate. After drying at $105^{\circ} \mathrm{C}$, $\mathrm{CaSO}_{4} \cdot 2 \mathrm{H}_{2} \mathrm{O}$ was transformed into $\mathrm{CaSO}_{4} \cdot 1 / 2 \mathrm{H}_{2} \mathrm{O}$ by high-temperature dehydration, and $\mathrm{CaSO}_{4} \cdot 1 / 2 \mathrm{H}_{2} \mathrm{O}$ will be converted back to $\mathrm{CaSO}_{4} \cdot 2 \mathrm{H}_{2} \mathrm{O}$ after water absorption. The chemical reaction of above process is shown in equation (3). After drying and hydrating, the crystals of regenerated $\mathrm{CaSO}_{4} \cdot 2 \mathrm{H}_{2} \mathrm{O}$ are tiny and heterogeneous, which increases 


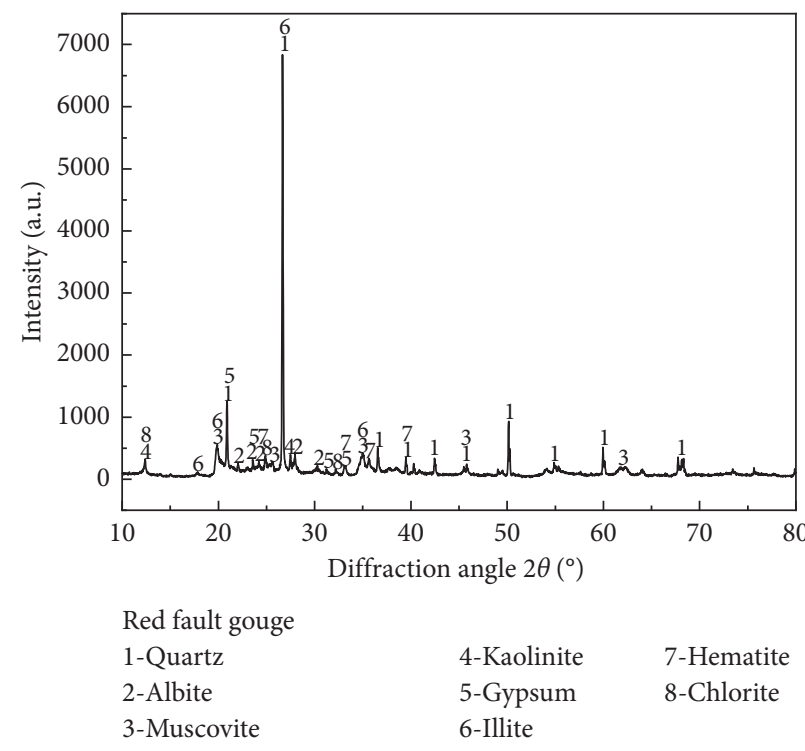

(a)

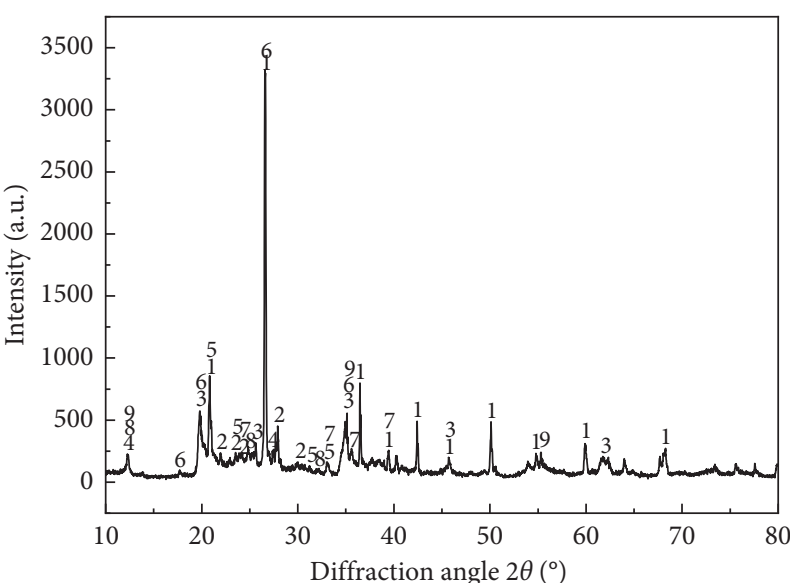

Multicolor fault gouge

$\begin{array}{lll}\text { 1-Quartz } & \text { 4-Kaolinite } & \text { 7-Hematite } \\ \text { 2-Albite } & \text { 5-Gypsum } & \text { 8-Chlorite } \\ \text { 3-Muscovite } & \text { 6-Illite } & \text { 9-Ettringite }\end{array}$

(b)

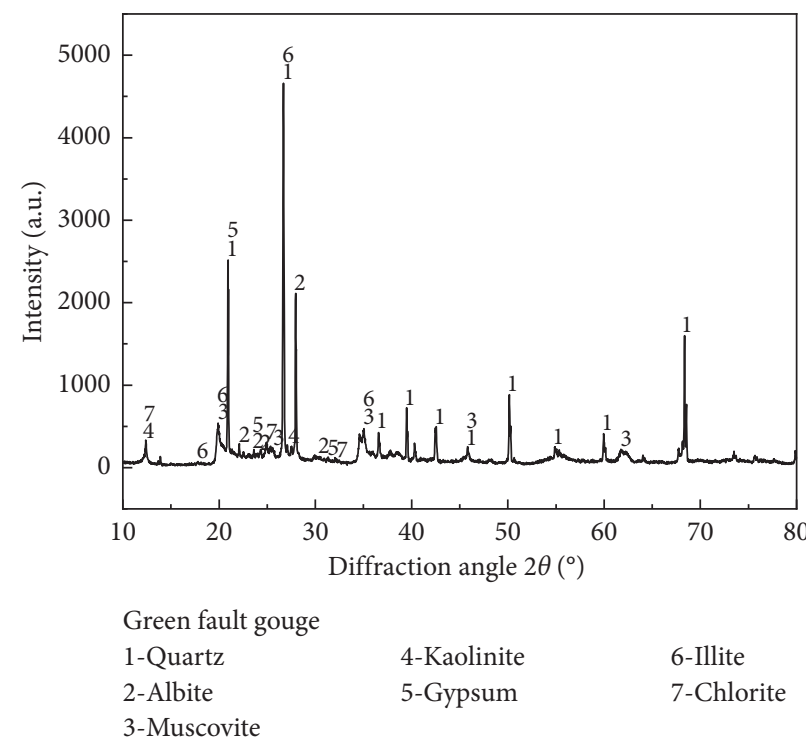

(c)

Figure 8: X-ray diffraction patterns.

TABLE 2: Semiquantitative analysis of mineral component in fault gouges (\%).

\begin{tabular}{lccccccccc}
\hline Fault gouge types & Quartz & Albite & Muscovite & Kaolinite & Gypsum & Illite & Hematite & Chlorite & Ettringtie \\
\hline Red fault gouge & 44.3 & 8.5 & 18.2 & 6.0 & 2.1 & 8.6 & 3.9 & 8.4 & - \\
Multicolor fault gouge & 33.0 & 9.6 & 22.3 & 6.6 & 2.7 & 8.5 & 1.7 & 10.3 & 5.3 \\
Green fault gouge & 27.5 & 18.2 & 25.9 & 7.6 & 2.0 & 9.5 & - & 9.3 \\
\hline
\end{tabular}

the porosity of gouge. This weakens the intergranular bonding as well as promotes the water absorption of clay minerals. Therefore, the mutual transformation between $\mathrm{CaSO}_{4} \cdot 2 \mathrm{H}_{2} \mathrm{O}$ and $\mathrm{CaSO}_{4} \cdot 1 / 2 \mathrm{H}_{2} \mathrm{O}$ accelerates the disintegration of fault gouge:

$$
2 \mathrm{CaSO}_{4} \cdot 2 \mathrm{H}_{2} \mathrm{O} \stackrel{\Delta}{\rightleftharpoons} \Delta 2 \mathrm{CaSO}_{4} \cdot \frac{1}{2} \mathrm{H}_{2} \mathrm{O}+3 \mathrm{H}_{2} \mathrm{O}
$$

\section{Results and Analysis of Ring Shear Test}

4.1. Testing Equipment and Methods. A Bromhead SRS-150 ring shear apparatus developed by GCTS Company was used to carry out the shear test, as shown in Figure 9. The shear device is mainly composed of sample box and loading board. In addition, the outer diameter $\left(R_{1}\right)$ and inner diameter $\left(R_{2}\right)$ 

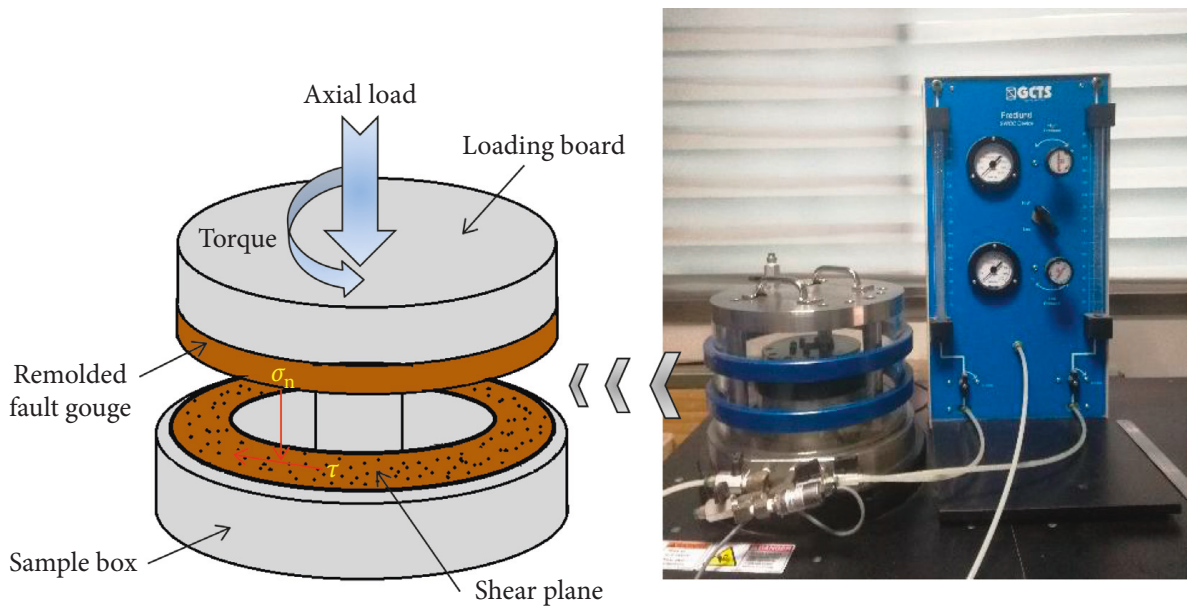

FIGURE 9: Bromhead ring shear apparatus and its shear device.

of sample box are $152 \mathrm{~mm}$ and $97 \mathrm{~mm}$, respectively. During the test, torque is applied by motor servo and axial load is controlled by pneumatic servo, which all applied to the loading board. The maximum shear stress is $1300 \mathrm{kPa}$, and maximum normal stress is $1000 \mathrm{kPa}$. Shearing angle can reach $\pm 360^{\circ}$ with the shear speed ranges from 0.001 to $360^{\circ}$ \% $\min$.

In shearing process, shear planes will be generated under the action of torque. It is assumed that normal stress $\left(\sigma_{\mathrm{n}}\right)$ and shear stress $(\tau)$ on the shear plane are uniformly distributed. Shear stress $(\tau)$ can be calculated by the moment of couple $(M)$, and the relationship between them can be shown as follows:

$$
M=\pi\left(R_{1}^{2}-R_{2}^{2}\right) \tau \times R_{a}=\tau \int_{R_{2}}^{R_{1}} 2 \pi R \times R \mathrm{~d} R,
$$

where $\pi\left(R_{1}^{2}-R_{2}^{2}\right) \tau$ is the sum of shear stress and $R_{\mathrm{a}}$ is average radius. According to equation (4), $\tau$ and $R_{\mathrm{a}}$ can be expressed as

$$
\begin{aligned}
\tau & =\frac{M}{\int_{R_{2}}^{R_{1}} 2 \pi R^{2} \mathrm{~d} R}=\frac{3 M}{2 \pi\left(R_{1}^{3}-R_{2}^{3}\right)}, \\
R_{\mathrm{a}} & =\frac{\int_{R_{2}}^{R_{1}} 2 \pi R^{2} \mathrm{~d} R}{\pi\left(R_{1}^{2}-R_{2}^{2}\right)}=\frac{2\left(R_{1}^{3}-R_{2}^{3}\right)}{3\left(R_{1}^{2}-R_{2}^{2}\right)} .
\end{aligned}
$$

In addition, shear displacement $(S)$ can be calculated by angular displacement $(\theta)$ and $R_{\mathrm{a}}$, which can be expressed as

$$
S=R_{\mathrm{a}} \theta .
$$

Before testing, the remolded fault gouge samples were prepared according to the natural dry density. Shear tests were performed on three types of remolded fault gouges with different water contents. Considering that the natural water content of fault gouge collected on site is $10 \%$ to $20 \%$, the water content $10 \%$ and $20 \%$ was adopted in tests. The normal stresses of each test group were set as 100, 200,300, 400, and $500 \mathrm{kPa}$, and the shear rate was all controlled as $2 \% \mathrm{~min}$ $(0.0364 \mathrm{~mm} / \mathrm{s})$.
4.2. Failure Modes of Shear Plane. The shear planes show three failure modes, as shown in Figure 10.

According to the statistics of shear planes, there are three failure modes: peeling failure (mode $a$ ), sliding failure (mode $b$ ), and grooved failure (mode $c$ ), and the failure results are shown in Table 3 . These failure modes are independent with the type of fault gouge, whose main influencing factors are water content $(\omega)$ and normal stress $(\sigma)$.

Under high normal stress, the fault gouge particles are subjected to large force and can be broken, which shows a sliding failure with the smooth failure plane. When under low normal stress and high water content, a higher pore water pressure will result in loose contact between particles during testing, and the shear plane shows peeling failure, which is characterized by a rough failure surface. However, when the water content and normal stress is low, the interaction between particles is strengthened under close contact, and large particles produce obvious scratches on the shear plane, which manifests as a grooved failure.

4.3. Shear Process and Shear Strength Parameters. Figure 11 shows the shear stress and shear displacement curves of the remolded red fault gouge, multicolor fault gouge, and green fault gouge with $10 \%$ and $20 \%$ water content under different normal stress.

The shear stress-shear displacement curves of the remolded fault gouges with different water contents show the same variation under a normal stress of 100 to $500 \mathrm{kPa}$ and have an obvious peak strength $\left(\tau_{\mathrm{p}}\right)$ and residual strength $\left(\tau_{\mathrm{r}}\right)$. The fault gouge shear strength is closely related to the normal stress and water content. Under the same normal stress, the peak strength and residual strength of the $10 \%$ water content are significantly greater than that of the $20 \%$ water content.

By fitting the peak strength, residual strength, and normal stress of the remolded fault gouges with different water contents, the shear strength parameters can be obtained, including peak cohesion $\left(c_{\mathrm{p}}\right)$, peak internal friction angle $\left(\varphi_{\mathrm{p}}\right)$, residual cohesion $\left(c_{\mathrm{r}}\right)$, and residual internal 


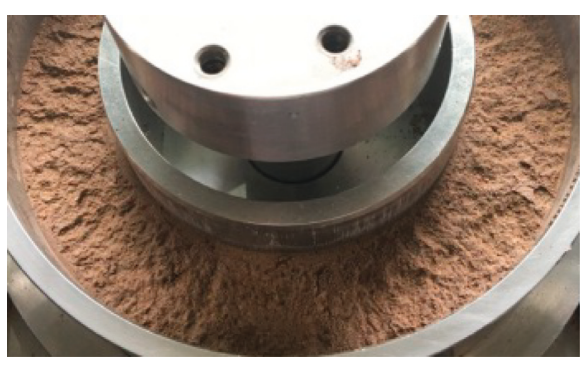

(a)

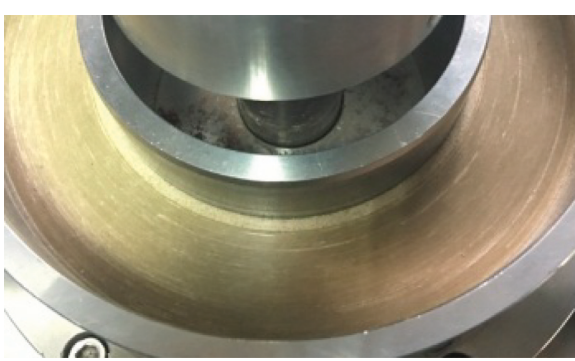

(b)

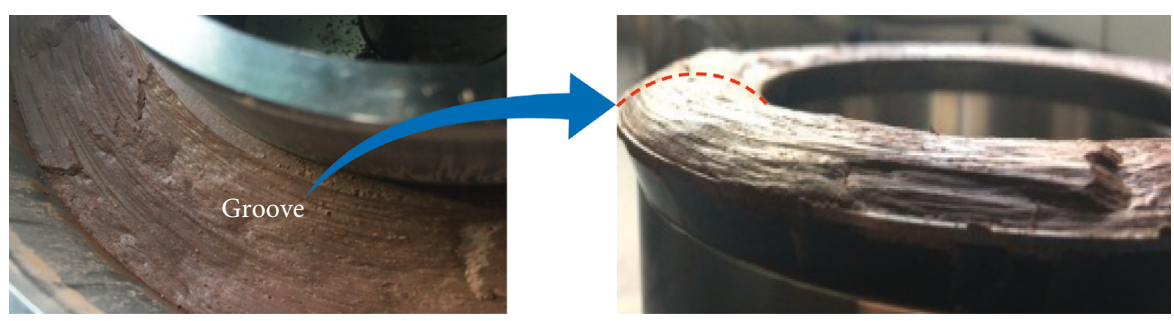

(c)

Figure 10: Shear surfaces of different failure modes. (a) Peeling failure. (b) Sliding failure. (c) Grooved failure.

TABLE 3: Statistics of failure modes of the shear plane.

\begin{tabular}{lcccccc}
\hline $\begin{array}{l}\sigma \\
(\mathrm{kPa})\end{array}$ & Red fault gouge & $\begin{array}{c}\text { Multicolor fault } \\
\text { gouge }\end{array}$ & \multicolumn{2}{c}{ Green fault gouge } \\
& $\omega=10 \%$ & $\omega=20 \%$ & $\omega=10 \%$ & $\omega=20 \%$ & $\omega=10 \%$ & $\omega=20 \%$ \\
\hline 100 & $a$ & $a$ & $a$ & $a$ & $a$ & $a$ \\
200 & $c$ & $a$ & $c$ & $a$ & $c$ & $a$ \\
300 & $b$ & $a$ & $c$ & $a$ & $b$ & $b$ \\
400 & $b$ & $b$ & $b$ & $b$ & $b$ & $b$ \\
500 & $b$ & $b$ & $b$ & $b$ & $b$ & $b$ \\
\hline
\end{tabular}

friction angle $\left(\varphi_{\mathrm{r}}\right) \cdot c_{\mathrm{p}}$ and $\varphi_{\mathrm{p}}$ are the cohesion and internal friction angles at peak strength, while $c_{\mathrm{r}}$ and $\varphi_{\mathrm{r}}$ are the strength parameters at residual strength. The fitting curves and shear strength parameters are as shown in Figure 12 and Table 4, respectively.

The shear strength parameters are negatively correlated with water content. With the same water content, the difference between $c_{\mathrm{p}}$ and $c_{\mathrm{r}}$ is significant, which can reach 50 to $80 \mathrm{kPa}$, while the difference between $\varphi_{\mathrm{p}}$ and $\varphi_{\mathrm{r}}$ is small. The directional arrangement of particles along the shear direction makes the shear stress reach its peak value. As shear continues, water in the test sample converges to the shear plane [33]. The water film around the particles on the shear plane becomes thicker, and the cohesion between particles is reduced because of the softening effect brought by water. However, the water migration cannot significantly affect the directional arrangement of particles [34]. It is obvious that the shear strength parameters are sensitive to the change of water content; with the increase of water content, the shear strength parameters decrease significantly.

\section{Discussion}

5.1. Relationship between Residual Strength and Peak Strength. There are obvious peak strengths and residual strengths in a fault gouge, and the shear strength parameters obtained from them are significantly different. The study of a fault gouge's shear strength cannot be limited to its residual strength parameters. When the residual strength is less than peak strength, fault gouge shows strain softening characteristics. In this paper, the "residual peak ratio" (denoted as d) proposed by Bishop et al. [35] is introduced to analyze the relationship between peak strength and residual strength, which can quantitatively describe the strain softening characteristics. The larger the $\lambda$ is, the closer the residual strength is to peak strength, and the less obvious the strain softening characteristics are. $\lambda$ can be expressed as

$$
\lambda=\frac{\tau_{\mathrm{r}}}{\tau_{\mathrm{p}}}
$$

As Figure 11 shows, it can be found that the strain softening characteristics are different with the change of normal stress. In this study, $\lambda$ and $\sigma$ present a logarithmic relationship, which can be shown as

$$
\lambda=a \ln \sigma+b,
$$

where $a$ and $b$ are fitting parameters, respectively. The related curves and fitting equations between $\lambda$ and $\sigma$ are shown in Figure 13.

$\lambda$ is positively correlated with normal stress and obeys a logarithmic relationship. Therefore, the residual strength gradually approaches to peak strength with the increase of normal stress, and the strain softening characteristics become weaker. Of course, the application of $\lambda$ is limited, which is especially suitable for strain softening stage. When $\lambda>1$, fault gouge may show strain hardening characteristics without obvious peak strength and residual strength. When $\lambda=1$, the residual strength is equal to peak strength and the normal stress value at this point is called "Normal Stress Threshold (NST)." NST is the critical point from strain softening to strain hardening. Fault gouge shows strain softening when $\sigma<\mathrm{NST}$. When $\sigma>\mathrm{NST}$, fault gouge is 

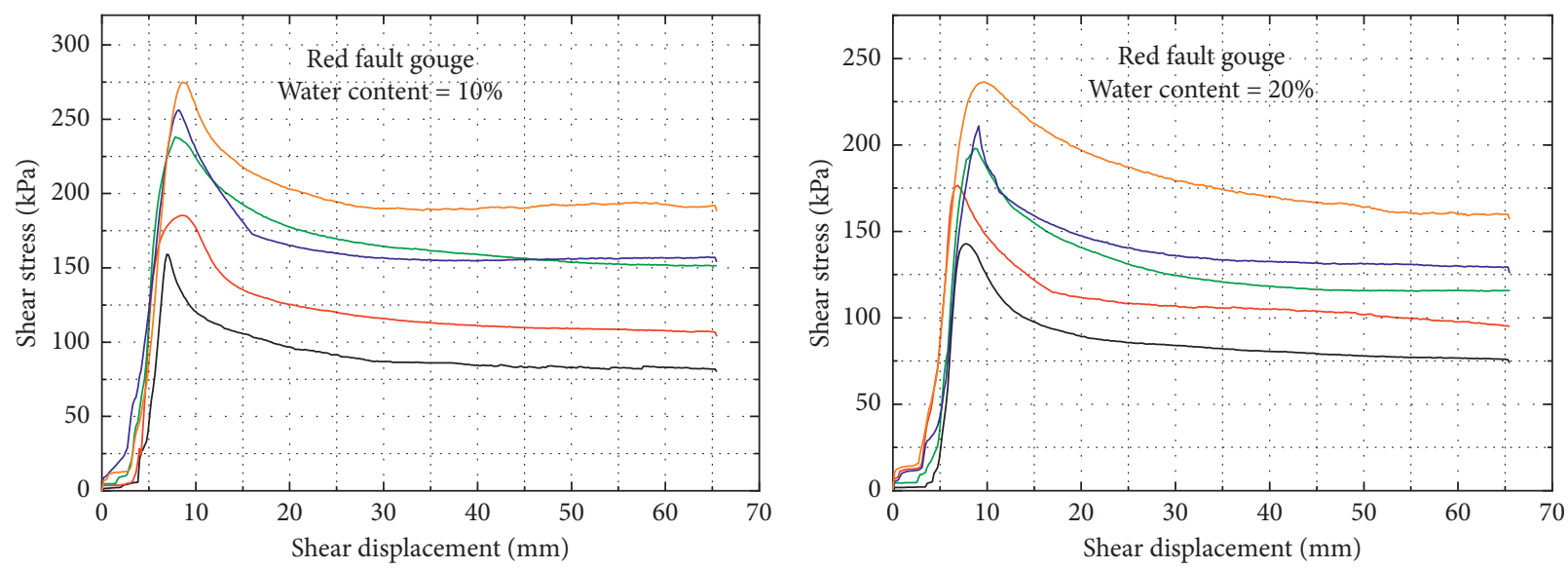

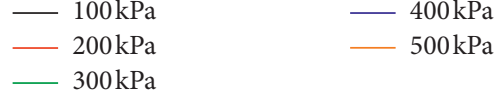

(a)
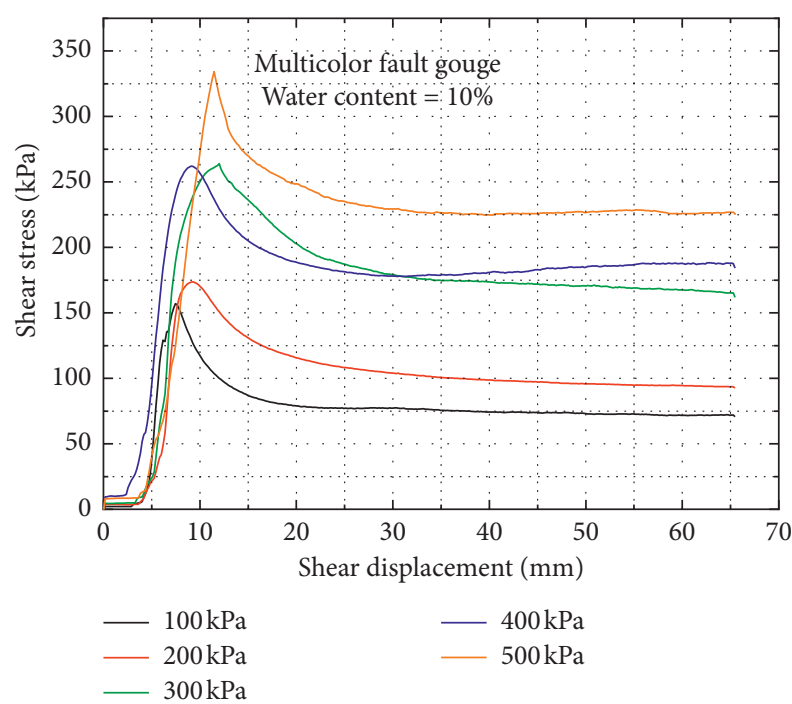

(c)
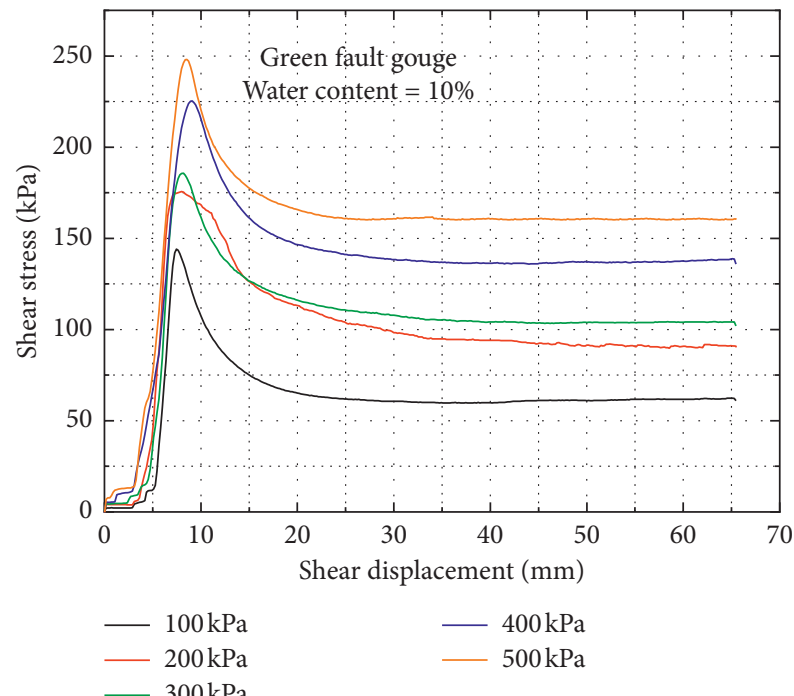

(e)

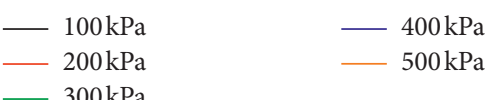

(b)
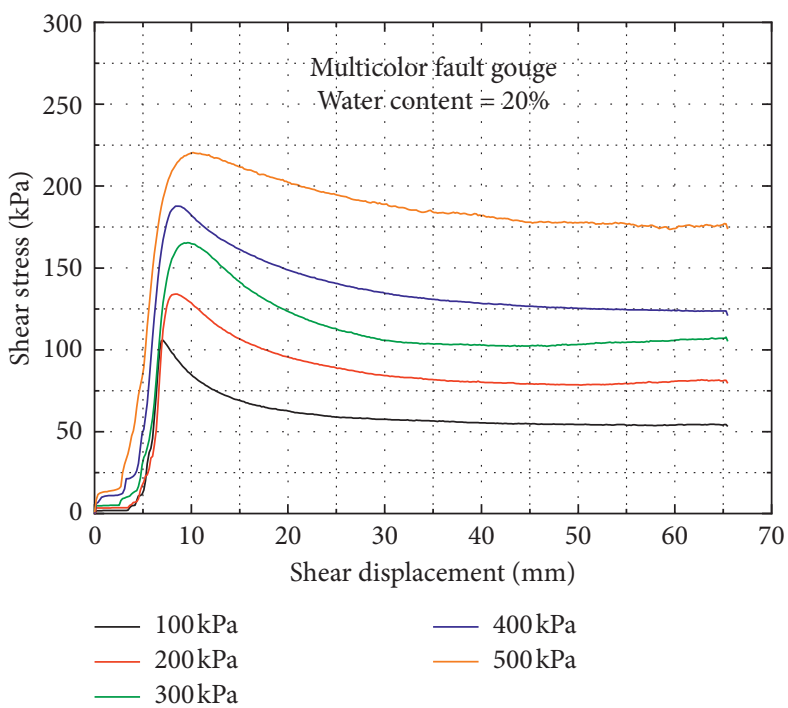

(d)
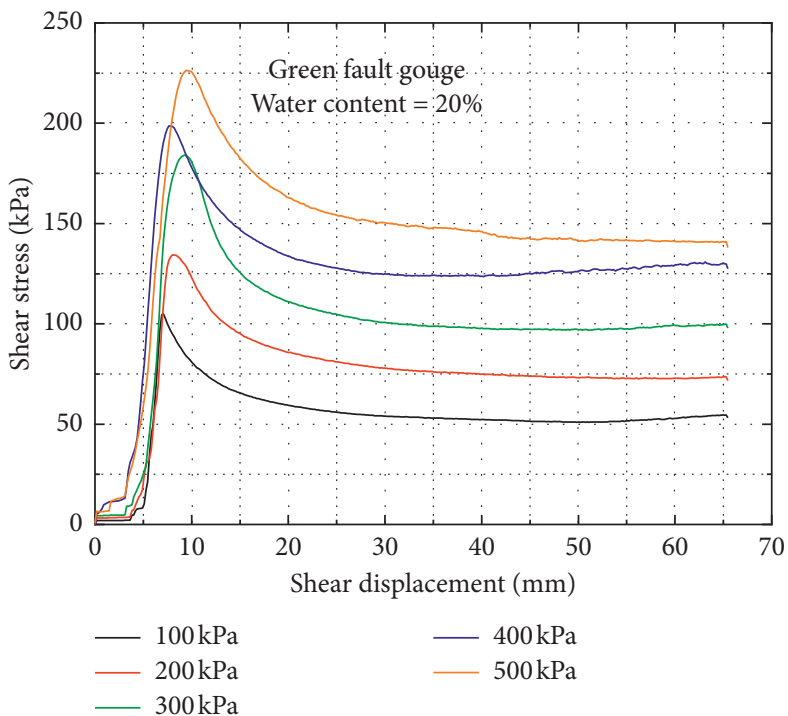

(f)

Figure 11: Shear stress and shear displacement curves. 

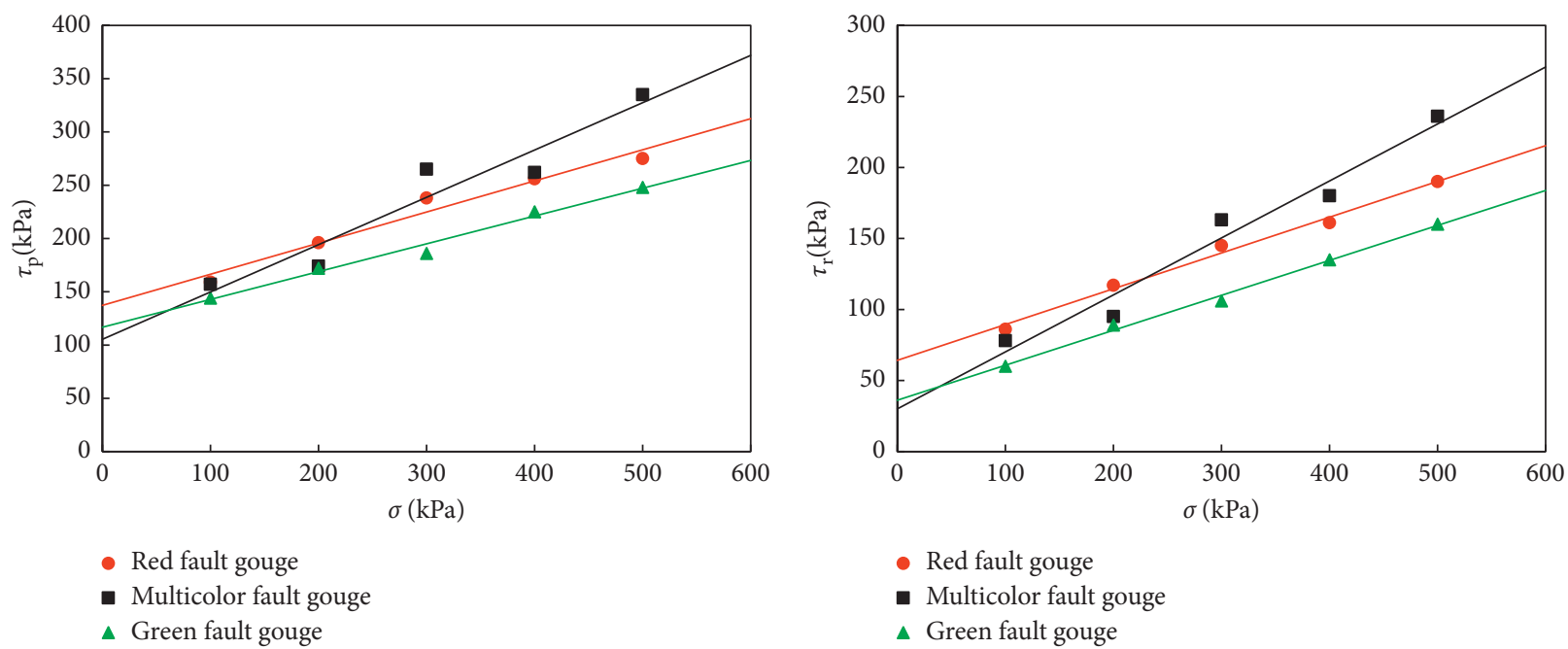

(a)
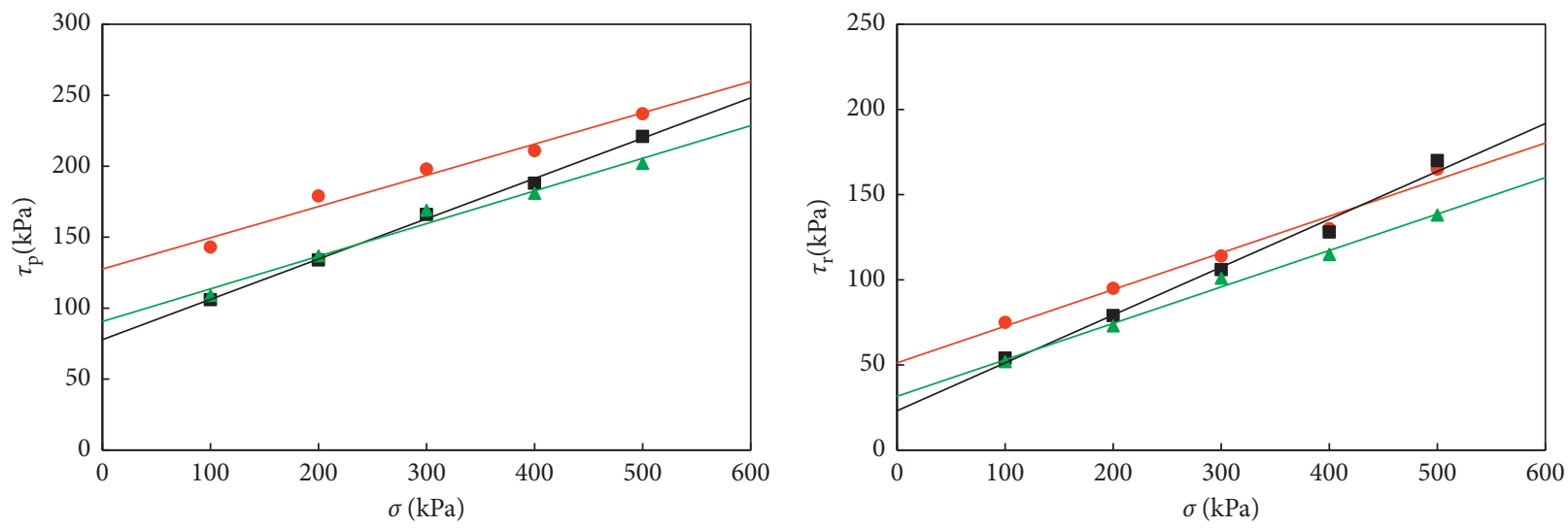

- Red fault gouge

- Multicolor fault gouge

- Green fault gouge

(c)

- Red fault gouge

- Multicolor fault gouge

- Green fault gouge

Figure 12: Fitting curves of peak strength and residual strength with normal stress. Peak strength at (a) $10 \%$ and (c) $20 \%$ water content. Residual strength at (b) $10 \%$ and (d) $20 \%$ water content.

TABLE 4: Parameters of shear strength.

\begin{tabular}{|c|c|c|c|c|c|}
\hline Fault gouge types & $\omega(\%)$ & $c_{\mathrm{p}}(\mathrm{kPa})$ & $\varphi_{\mathrm{p}}\left({ }^{\circ}\right)$ & $c_{\mathrm{r}}(\mathrm{kPa})$ & $\varphi_{\mathrm{r}}\left(^{\circ}\right)$ \\
\hline \multirow{2}{*}{ Red fault gouge } & 10 & 137.2 & 16.3 & 64.2 & 14.1 \\
\hline & 20 & 127.6 & 12.4 & 51.3 & 12.1 \\
\hline \multirow{2}{*}{ Multicolor fault gouge } & 10 & 105.4 & 23.9 & 30.1 & 21.9 \\
\hline & 20 & 77.8 & 15.9 & 23.1 & 15.7 \\
\hline \multirow{2}{*}{ Green fault gouge } & 10 & 116.7 & 14.6 & 36.2 & 13.8 \\
\hline & 20 & 90.6 & 12.9 & 31.6 & 12.1 \\
\hline
\end{tabular}

characterized by strain hardening, and there is no obvious stable value of shear stress. The NST values calculated from fitting equations in Figure 13 are shown in Table 5.

The NST fault gouge values at $10 \%$ water content are greater than those at $20 \%$. This difference is obvious in the red fault gouge and multicolor fault gouge but not in the green fault gouge. The NST values for natural water content can be deduced as follows: green fault gouge is approximately 6.8 to $6.9 \mathrm{MPa}$, multicolor fault gouge is 3.0 to 4.5 $\mathrm{MPa}$, while red fault gouge is 11.0 to $14.7 \mathrm{MPa}$. The strain softening property clearly weakens with an increase in coarse particle content, which shows that the "Residual Peak Ratio" becomes larger under the same normal stress. This phenomenon has been revealed in the previous studies $[33,36]$.

In the selection of in situ strength parameters, if the normal stress of fault gouge is less than the NST value, the 


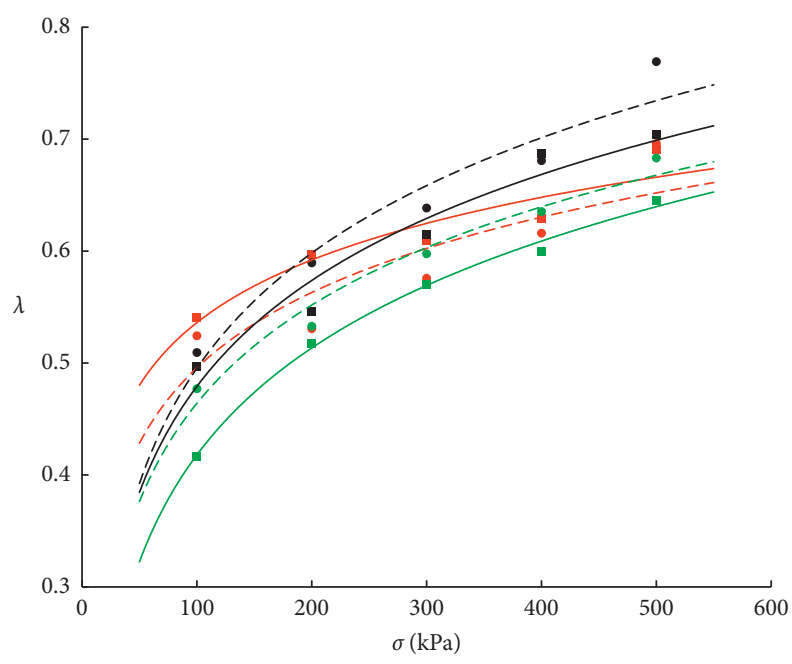

$$
\begin{aligned}
& \text { - Red-10\% (test data) } \\
& \text { - Red-20\% (test data) } \\
& \text { - Multicolor-10\% (test data) } \\
& \text { - Multicolor-20\% (test data) } \\
& \text { - Green-10\% (test data) } \\
& \text { - Green-20\% (test data) } \\
& \text { — Red-10\% (fitting) } \\
& \lambda=0.081 \ln (\sigma)+0.164 \\
& \text { - - Red-20\% (fitting) } \\
& \lambda=0.097 \ln (\sigma)+0.049 \\
& \text { — Multicolor-10\% (fitting) } \\
& \lambda=0.137 \ln (\sigma)-0.150 \\
& \text { - - Multicolor-20\% (fitting) } \\
& \lambda=0.149 \ln (\sigma)-0.189 \\
& \text { - Green-10\% (fitting) } \\
& \lambda=0.138 \ln (\sigma)-0.217 \\
& \text { _ - - Green-20\% (fitting) } \\
& \lambda=0.127 \ln (\sigma)-0.119
\end{aligned}
$$

FIGURE 13: Fitting curves and fitting equations of $\lambda$ value with $\sigma$.

TABLE 5: NST fault gouge values.

\begin{tabular}{lcc}
\hline Fault gouge types & $\omega(\%)$ & NST $(\mathrm{MPa})$ \\
\hline \multirow{2}{*}{ Red fault gouge } & 10 & 14.7 \\
& 20 & 11.0 \\
\hline \multirow{2}{*}{ Multicolor fault gouge } & 10 & 4.5 \\
& 20 & 3.0 \\
\hline \multirow{2}{*}{ Green fault gouge } & 10 & 6.9 \\
& 20 & 6.8 \\
\hline
\end{tabular}

peak strength parameters can therefore be selected prior. Oppositely, when the normal stress is greater than the NST value, the selection of strength parameters will be more complicated because there is no peak strength and stable strength value. Therefore, the introduction of NST is helpful in reasonable selections of fault gouge strength parameters.

5.2. Relationship between Residual Strength and Normal Stress. Defining the ratio of residual strength to normal stress as the "shear stress ratio," denoted as $R_{\mathrm{s}}$ :

$$
R_{\mathrm{s}}=\frac{\tau_{\mathrm{r}}}{\sigma} .
$$

As shown in Figure 14, $R_{\mathrm{s}}$ and $\sigma$ present a power function relationship within different water contents, which can be expressed as

$$
R_{\mathrm{s}}=m \sigma^{n}
$$

where $m$ and $n$ are fitting parameters, respectively.

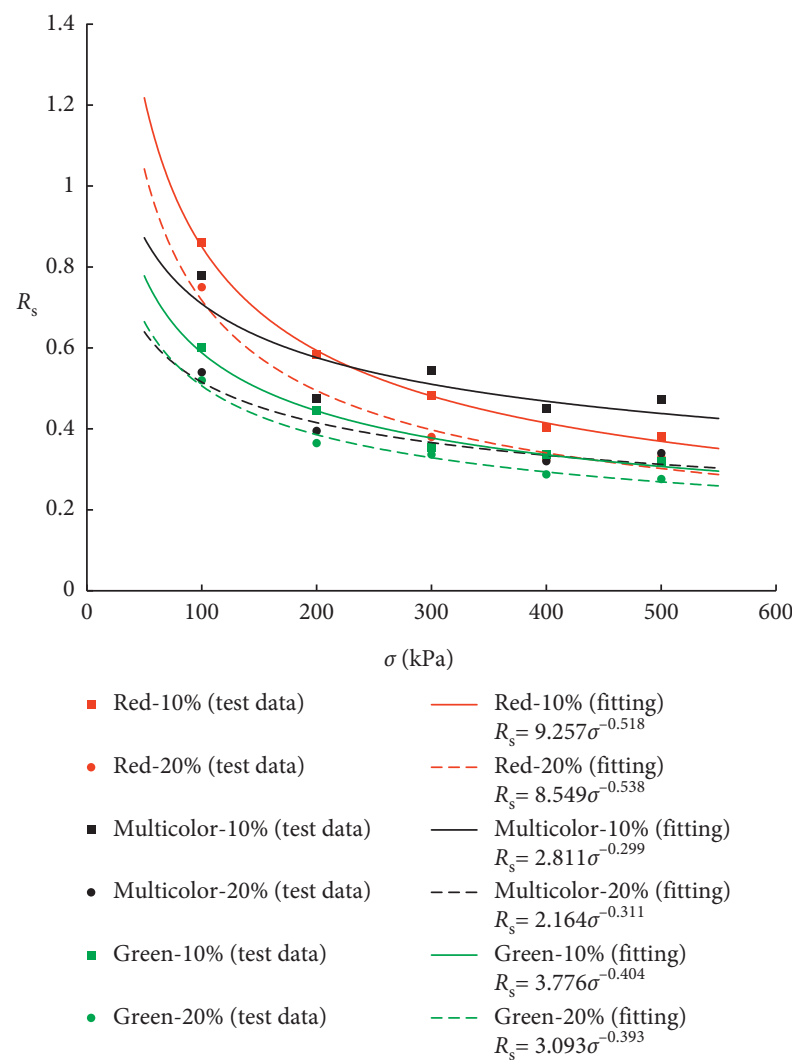

FIGURE 14: Fitting curves and fitting equations of $R_{\mathrm{s}}$ with $\sigma$.

$R_{\mathrm{s}}$ shows a negative correlation with normal stress and tends to be stable. When the normal stress increases to a certain value, the residual strength and normal stress become a linear relationship. Combined with equations (7)(10), the residual strength and peak strength under any normal stress can be obtained as

$$
\begin{gathered}
\tau_{\mathrm{r}}=m \sigma^{n+1}, \\
\tau_{\mathrm{p}}=\frac{m \sigma^{n+1}}{a \ln \sigma+b} .
\end{gathered}
$$

According to equations (11) and (12), the peak strength parameters $\left(c_{\mathrm{p}}\right.$ and $\left.\varphi_{\mathrm{p}}\right)$ and residual strength parameters $\left(c_{\mathrm{r}}\right.$ and $\left.\varphi_{\mathrm{r}}\right)$ can be obtained under any normal stress. The fault gouge shear strength parameters are obviously correlated with normal stress and present a nonlinear relationship. Equations (11) and (12) quantitatively reflect the nonlinear variation in the shear strength parameters under different stress states, which means that more reasonable fault gouge parameters can be obtained. Taking the red fault gouge as an example, the shear strength parameter curves with normal stress variation at $10 \%$ and $20 \%$ water contents are shown in Figure 15.

Within the normal stress range ( 0 to $7 \mathrm{MPa}$ ) shown in Figure 15, the shear strength parameters at $10 \%$ water content are significantly greater than those of $20 \%$ water content. With an increase of normal stress, the decrease rate of the internal friction angle $\left(\varphi_{\mathrm{p}}\right.$ and $\left.\varphi_{\mathrm{r}}\right)$ and the increase rate of cohesion $\left(c_{\mathrm{p}}\right.$ and $\left.c_{\mathrm{r}}\right)$ decline gradually. Notably, the 


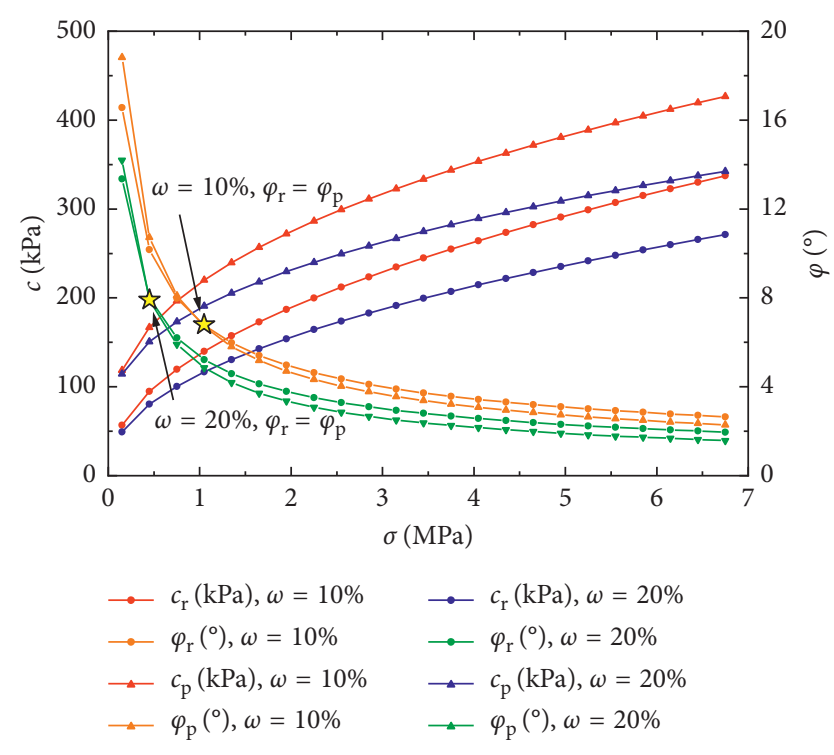

Figure 15: Curves of shear strength parameters (red fault gouge).

decrease rate of $\varphi_{\mathrm{p}}$ is higher than that of $\varphi_{\mathrm{r}}$. In the initial stage, when the normal stress is lower, $\varphi_{\mathrm{p}}>\varphi_{\mathrm{r}}$. With an increase in normal stress, there is a critical point of the internal friction angle where $\varphi_{\mathrm{p}}=\varphi_{\mathrm{r}}$. As normal stress continues to increase, $\varphi_{\mathrm{r}}>\varphi_{\mathrm{p}}$. In addition, the higher the water content, the earlier the internal friction angle critical point appears.

5.3. Comparison of Residual Strength of Different Soils. To analyze the specificity of fault gouge mechanical properties, the residual strengths of clay and loess are selected from references to give a comparison [35, 37-43]. The fitting curves of "shear stress ratio $\left(R_{\mathrm{s}}\right)$ " and normal stress (0 to $600 \mathrm{kPa}$ ) of different soils are obtained as shown in Figure 16.

For the three types of soils, the "shear stress ratio" and normal stress rates show a strong negative exponential power relationship. With an increase in normal stress, the nonlinear characteristics of curves decrease significantly. However, there are significant differences in normal stress when the "shear stress ratio" of each soil reaches a stable state. Bishop et al. [35] considered that when the normal stress is less than $150 \mathrm{kPa}$, there is a strong nonlinear relationship between the residual strength and normal stress in clay. At the normal stress of $150 \mathrm{kPa}$, the clay curve's curvature is the smallest, followed by the fault gouge and loess. This indicates that the "shear stress ratio" of clay under this normal stress state is the most stable, while the nonlinear trend for loess is the strongest, and the fault gouge is between them.

Skempton [44] found that the residual strength of soil is negatively correlated with clay particle content. During shearing, with the migration of water, the swell-shrink characteristic of the clay particles reduces the residual strength. The fault gouge residual strength is between clay and loess, which indicates that the fault gouge's clay particle content is also between the other two soils. However, this is

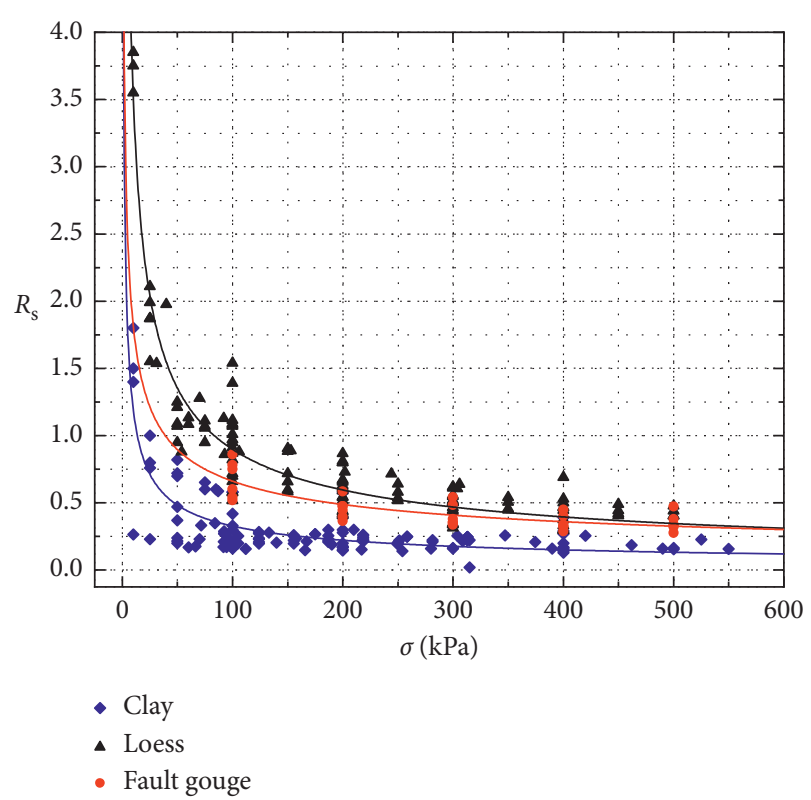

FIGURE 16: Fitting curves of $R_{\mathrm{s}}$ with normal stress for different soils.

only a qualitative judgment of the residual strength from clay particle content.

It is worth mentioning that some references do not cover the mineral composition of soil, so this paper does not carry out statistics on mineral composition to explore the intensity characteristics of different soils. In the future work, the relevant research will be carried out.

\section{Conclusions}

The shear strength parameters of the remolded fault gouge with $10 \%$ and $20 \%$ water content are obtained by the ring shear test. The shear strength properties under different water contents and normal stress states are analyzed, and we reached the following conclusions:

(1) There is a single peak on the particle size distribution curve of the multicolor fault gouge and green fault gouge. Meanwhile, the red fault gouge shows a double peak, and its gradation is worse than other fault gouges. The coarse particle content of the three types of fault gouges is as follows: multicolor fault gouge $>$ green fault gouge $>$ red fault gouge. With an increase in coarse particle content, the strain softening property tends to be weak during the shear process.

(2) Quartz is the most abundant in nonclay minerals. The main clay minerals are chlorite and illite, followed by kaolinite. Differences in mineral composition make fault gouges appear in different colors. Besides clay minerals, gypsum shows positive effects on the disintegration of fault gouges.

(3) Influenced by water content and normal stress, the shear planes can be defined as three failure modes: peeling failure, grooved failure, and sliding failure. The fault gouges have obvious peak strength and 
residual strength under normal stress states of 100 to $500 \mathrm{kPa}$. Under the same water content, the difference between $c_{\mathrm{p}}$ and $c_{\mathrm{r}}$ is 50 to $80 \mathrm{kPa}$, while the difference between $\varphi_{\mathrm{p}}$ and $\varphi_{\mathrm{r}}$ is small.

(4) The new parameter "normal stress threshold" is defined, which is helpful in reasonably using the shear strength parameters. When normal stress is greater than the "normal stress threshold," the peak strength and residual strength of fault gouges are basically equal. Additionally, the "normal stress threshold" of each fault gouge is significantly different.

(5) Shear strength parameters can be calculated under any normal stress state by equations that are fitted by the residual strength with normal stress and the peak strength. With a change in normal stress, there is a critical point that reflects the equivalence relationship of $\varphi_{\mathrm{p}}$ and $\varphi_{\mathrm{r}}$. In addition, the higher the water content, the earlier the critical point appears. As a special soil, a fault gouge is significantly different from loess and clay. Clay particle contents can qualitatively explain the reason why the residual strength of fault gouges is between clay and loess.

\section{Data Availability}

The data used to support the findings of this study are included within the article.

\section{Conflicts of Interest}

The authors declare that there are no conflicts of interest regarding the publication of this paper.

\section{Acknowledgments}

This research was funded by the National Natural Science Foundation of China (Grant nos. 41790443, 41807246, and 41927806), Natural Science Foundation of Shaanxi Province (Grant no. 2018JQ4017), and Key Laboratory of Rock Mechanics and Geohazards of Zhejiang Province (Grant no. PCMGH-2016-Z-03). This work was also supported by the Scientific Innovation Practice Project of Postgraduates of Chang'an University (Grant no. 300103002033) and the Fundamental Research Funds for the Central Universities (Grant nos. 300102218412 and 300102219213). We acknowledge Jiangbo $\mathrm{Xu}$ and Wei Wei who helped us to improve the readability of this test. We would further appreciate Keke Zhang who helped us for the sampling works.

\section{References}

[1] W. Li, Y. Dong, A. Guo, X. Liu, and D. Zhou, "Chronology and tectonic significance of Cenozoic faults in the Liupanshan Arcuate tectonic belt at the northeastern margin of the Qinghai-Tibet plateau," Journal of Asian Earth Sciences, vol. 73, pp. 103-113, 2013.

[2] F. Meng, H. Zhou, Z. Wang et al., "Experimental study of factors affecting fault slip rockbursts in deeply buried hard rock tunnels," Bulletin of Engineering Geology and The Environment, vol. 76, no. 3, pp. 1167-1182, 2017.

[3] Q.-S. Wu, L. Jiang, and Q. Wu, "Study on the law of mining stress evolution and fault activation under the influence of normal fault," Acta Geodynamica Et Geomaterialia, vol. 14, pp. 357-369, 2017.

[4] C. H. Scholz, "Wear and gouge formation in brittle faulting," Geology, vol. 15, no. 6, pp. 493-495, 1987.

[5] N. Geng, X. Yao, and Y. Chen, "Primary study on mechanical properties of the gouge for five large faults in China," Earthquake Research in China, vol. 1, no. 4, pp. 60-65, 1985.

[6] C. Morrow, L. Q. Shi, and J. Byerlee, "Permeability and strength of San Andreas fault gouge under high pressure," Geophysical Research Letters, vol. 8, no. 4, pp. 325-328, 1981.

[7] T. Numelin, C. Marone, and E. Kirby, "Frictional properties of natural fault gouge from a low-angle normal fault, Panamint Valley, California," Tectonics, vol. 26, no. 2, 2007.

[8] Y. Liu, C. Lu, T. Zhao, and H. Zhang, "Effects of particle size on fault gouge frictional characteristics and associated acoustic emission," Advances in Civil Engineering, vol. 2018, Article ID 6953165, 11 pages, 2018.

[9] Q. Liu, E. Button, and K. Klima, "Investigation for probabilistic prediction of shear strength properties of clay-rich fault gouge in the Austrian Alps," Engineering Geology, vol. 94, no. 1-2, pp. 103-121, 2007.

[10] B. Li and J. Deng, "Experimental study of physic-mechanical properties of fault materials from Shenxigou rupture of Longmenshan fault," Chinese Journal of Rock Mechanics and Engineering, vol. 30, no. supp. 1, pp. 2653-2660, 2011.

[11] L. Zhang and C. He, "Frictional properties of clay minerals and their effect on fault behaviour," Progress in Geophysics, vol. 29, no. 2, pp. 620-629, 2014.

[12] Z. Wu, P. J. Barosh, D. Hu et al., "Hazards posed by active major faults along the Golmud-Lhasa railway route, Tibetan Plateau, China," Engineering Geology, vol. 74, no. 3-4, pp. 163-182, 2004.

[13] R. Liu, B. Li, L. Yu, Y. Jiang, and H. Jing, “A discrete-fracturenetwork fault model revealing permeability and aperture evolutions of a fault after earthquakes," International Journal of Rock Mechanics and Mining Sciences, vol. 107, pp. 19-24, 2018.

[14] H. Lan, C. Zhou, C. Lee, S. J. Wang, and F. Q. Wu, "Rainfallinduced landslide stability analysis in response to transient pore pressure-a case study of natural terrain landslide in Hong Kong," Science in China Ser.E Technological Sciences, vol. 46, no. S1, pp. 52-68, 2003.

[15] C.-G. Yan, Q. Wan, Y. Xu, Y. Xie, and P. Yin, "Experimental study of barrier effect on moisture movement and mechanical behaviors of loess soil," Engineering Geology, vol. 240, pp. 1-9, 2018.

[16] J. Xu, W. Wei, H. Bao et al., "The failure models of loess stacked dam: a case study in Ansai area," Bulletin of Engineering Geology and the Environment, 2019.

[17] C. A. Morrow, D. E. Moore, and D. A. Lockner, "The effect of mineral bond strength and adsorbed water on fault gouge frictional strength," Geophysical Research Letters, vol. 27, no. 6, pp. 815-818, 2000.

[18] M. Rempe, S. Smith, T. Mitchell, T. Hirose, and G. Di Toro, "The effect of water on strain localization in calcite fault gouge sheared at seismic slip rates," Journal of Structural Geology, vol. 97, no. 1, pp. 104-117, 2017.

[19] B. Liu and D. Nie, "Study on relation between strength parameter and water content of gouge," Chinese Journal of Geotechnical Engineering, vol. 28, no. 12, pp. 2164-2167, 2006. 
[20] P. Wang, W. Tan, X. Ma et al., "Study on relationship between strength parameter and water content of fault gouge with different degree of consolidation," Rock and Soil Mechanics, vol. 40, no. 5, pp. 1-6, 2019.

[21] D. R. Scott, D. A. Lockner, J. D. Byerlee, and C. G. Sammis, "Triaxial testing of Lopez fault gouge at $150 \mathrm{MPa}$ mean effective stress," Pure and Applied Geophysics PAGEOPH, vol. 142, no. 3-4, pp. 749-775, 1994.

[22] D. R. Scott, C. J. Marone, and C. G. Sammis, "The apparent friction of granular fault gouge in sheared layers," Journal of Geophysical Research, vol. 99, no. B4, pp. 7231-7246, 1994.

[23] S.-I. Uehara and T. Shimamoto, "Gas permeability evolution of cataclasite and fault gouge in triaxial compression and implications for changes in fault-zone permeability structure through the earthquake cycle," Tectonophysics, vol. 378, no. 34, pp. 183-195, 2004.

[24] Z. Lu and C. He, "Friction of foliated fault gouge with a biotite interlayer at hydrothermal conditions," Tectonophysics, vol. 740-741, pp. 72-92, 2018.

[25] H. Bao, F. Q. Wu, and J. R. Niu, "Effects of test procedures and lithology on estimating the mode I fracture toughness of rocks using empirical relations," Materialwissenschaft und Werkstofftechnik, vol. 49, no. 8, pp. 951-962, 2018.

[26] H. Lan, J. Chen, and R. Macciotta, "Universal confined tensile strength of intact rock," Scientific Reports, vol. 9, no. 1, pp. 1-9, 2019.

[27] K. Sassa, H. Fukuoka, G. Wang, and N. Ishikawa, "Undrained dynamic-loading ring-shear apparatus and its application to landslide dynamics," Landslides, vol. 1, no. 1, pp. 7-19, 2004.

[28] H. Zheng, H. Lin, W. Zhou et al., "Revegetation has increased ecosystem water-use efficiency during 2000-2014 in the Chinese Loess Plateau: evidence from satellite data," Ecological Indicators, vol. 102, pp. 507-518, 2019.

[29] H. Bao, Y. Zhai, H. Lan, K. Zhang, Q. Qi, and C. Yan, "Distribution characteristics and controlling factors of vertical joint spacing in sand-mud interbedded strata," Journal of Structural Geology, vol. 128, Article ID 103886, , 2019.

[30] H. Chao, Q. Deng, J. Li, W. Zhicai, and M. Hongmin, "Study on active faults in quaternary unconsolidated sediments by microstructural method," Earthquake Research in China, vol. 16, no. 2, pp. 120-126, 2002.

[31] W. Chen, G. Lin, W. Liu et al., "Physical and mechanical properties of weathered green and red mudstones," Chinese Journal of Rock Mechanics and Engineering, vol. 35, no. 12, pp. 2572-2582, 2016.

[32] T. P. Gautam and A. Shakoor, "Slaking behavior of claybearing rocks during a one-year exposure to natural climatic conditions," Engineering Geology, vol. 166, pp. 17-25, 2013.

[33] D. Liu and X. Chen, "Laboratory test and parameter back analysis of residual strength of slip zone soils," Journal of South China University of Technology, vol. 42, no. 2, pp. 81-87, 2014.

[34] A. W. Skempton, "First-time slides in over-consolidated clays," Géotechnique, vol. 20, no. 3, pp. 320-324, 1970.

[35] A. W. Bishop, G. E. Green, V. K. Garga, A. Andresen, and J. D. Brown, "A new ring shear apparatus and its application to the measurement of residual strength," Géotechnique, vol. 21, no. 4, pp. 273-328, 1971.

[36] H. Lan, C. D. Martin, and B. Hu, "Effect of heterogeneity of brittle rock on micromechanical extensile behavior during compression loading," Journal of Geophysical Research Solid Earth, vol. 115, no. B1, 2010.

[37] H. T. Eid, K. H. Rabie, and D. Wijewickreme, "Drained residual shear strength at effective normal stresses relevant to soil slope stability analyses," Engineering Geology, vol. 204, pp. 94-107, 2016.

[38] B. P. Wen, A. Aydin, N. S. Duzgoren-Aydin, Y. R. Li, H. Y. Chen, and S. D. Xiao, "Residual strength of slip zones of large landslides in the Three Gorges area, China," Engineering Geology, vol. 93, no. 3-4, pp. 82-98, 2007.

[39] N. Kalteziotis, "The residual shear strength of some hellenic clayey soils," Geotechnical and Geological Engineering, vol. 11, no. 2, pp. 125-145, 1993.

[40] S. Kimura, S. Nakamura, and S. B. Vithana, "Influence of effective normal stress in the measurement of fully softened strength in different origin landslide soils," Soil and Tillage Research, vol. 145, pp. 47-54, 2015.

[41] B.-P. Wen and Y.-J. Yan, "Influence of structure on shear characteristics of the unsaturated loess in Lanzhou, China," Engineering Geology, vol. 168, pp. 46-58, 2014.

[42] T. A. Dijkstra, C. D. F. Rogers, I. J. Smalley, E. Derbyshire, Y. J. Li, and X. M. Meng, "The loess of north-central China: geotechnical properties and their relation to slope stability," Engineering Geology, vol. 36, no. 3-4, pp. 153-171, 1994.

[43] C. Ye, Y. Zhu, Y. Liu, and Y. X. Song, "Experimental study on the anisotropy and unloading deformation characteristics of intact loess," China Railway Science, vol. 35, no. 6, pp. 1-6, 2014.

[44] A. W. Skempton, "Residual strength of clays in landslides, folded strata and the laboratory," Géotechnique, vol. 35, no. 1, pp. 3-18, 1985. 


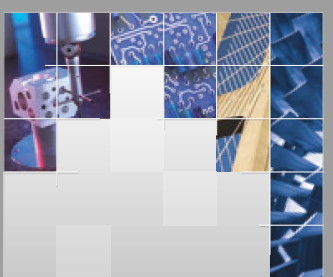

\section{Enfincering}
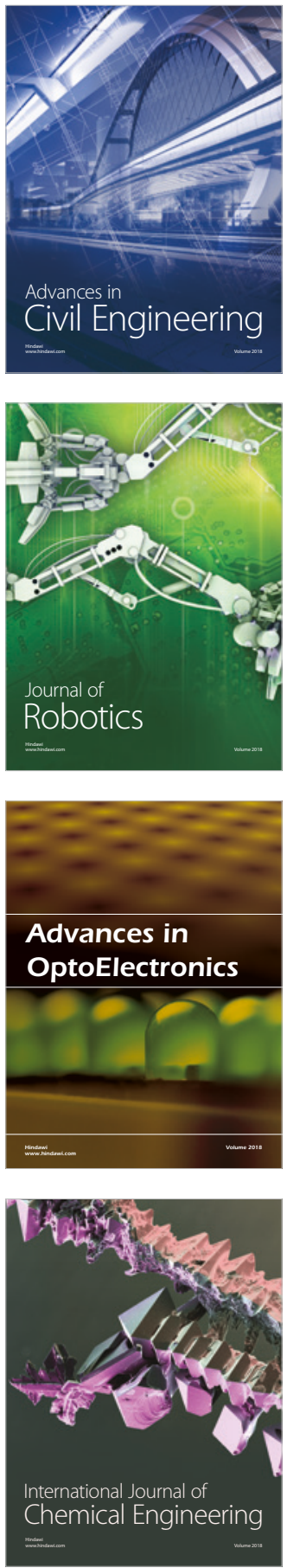

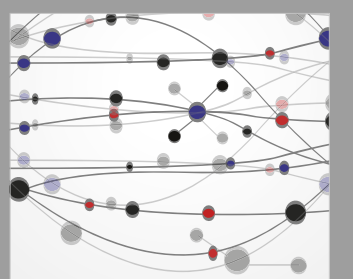

\section{Rotating \\ Machinery}

The Scientific World Journal

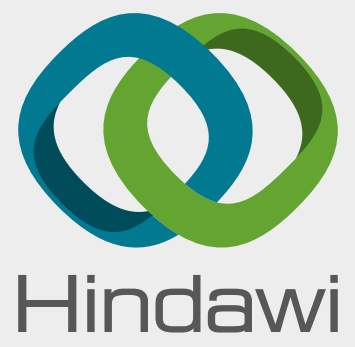

Submit your manuscripts at

www.hindawi.com
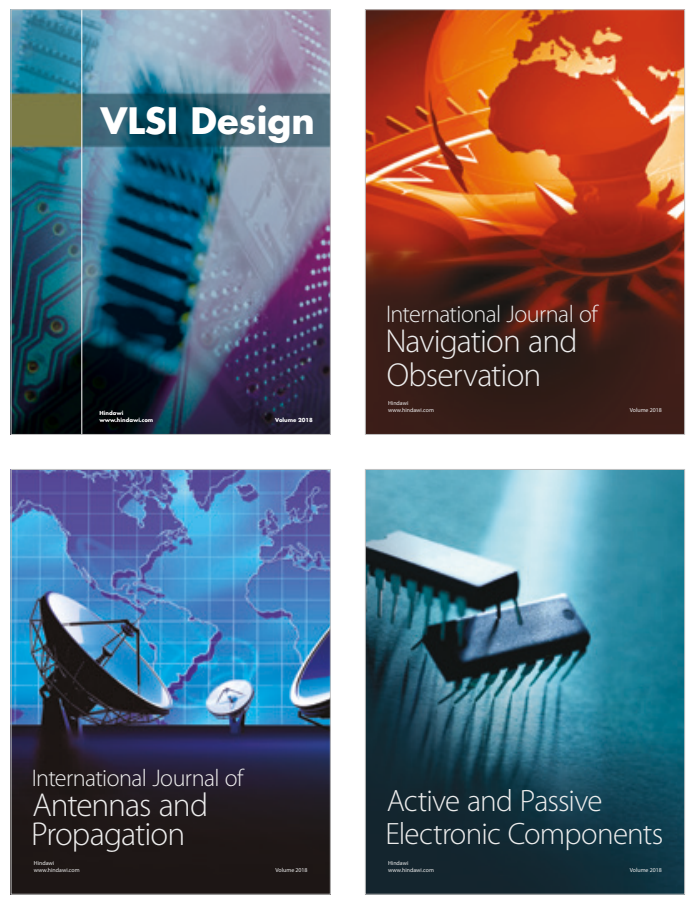
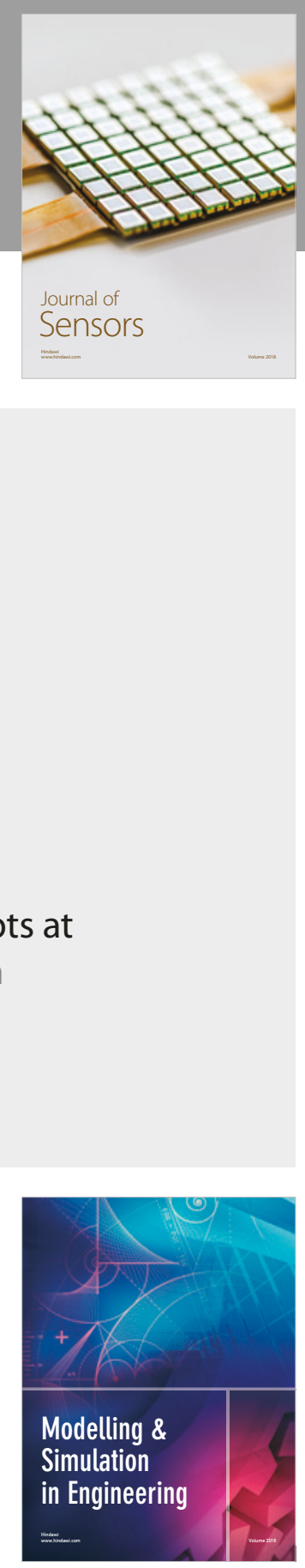

\section{Advances \\ Multimedia}
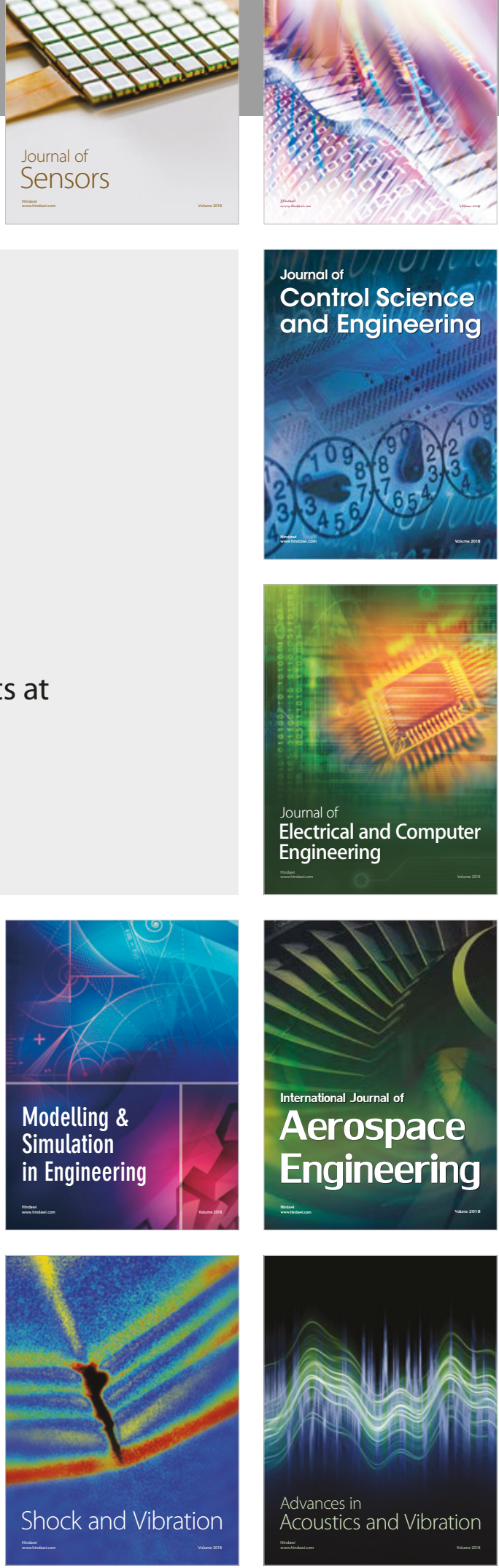